\title{
Review \\ The Lost Neural Hierarchy of the Autistic Self-Locked-Out of the Mental Self and Its Default-Mode Network
}

\author{
Fuxin Lian ${ }^{1,2}$ (D) and Georg Northoff $2, *$ (D) \\ 1 Institute of Psychological Sciences, School of Education, Hangzhou Normal University, \\ Hangzhou 311121, China; fxlian@hznu.edu.cn \\ 2 Institute of Mental Health Research, University of Ottawa, Ottawa, ON K1Z 7K4, Canada \\ * Correspondence: georg.northoff@theroyal.ca; Tel.: +1-613-722-6521 (ext. 6870)
}

Citation: Lian, F.; Northoff, G. The Lost Neural Hierarchy of the Autistic Self-Locked-Out of the Mental Self and Its Default-Mode Network. Brain Sci. 2021, 11, 574. https://doi.org/ 10.3390/brainsci11050574

Academic Editor: Cosimo Urgesi

Received: 11 March 2021

Accepted: 23 April 2021

Published: 29 April 2021

Publisher's Note: MDPI stays neutral with regard to jurisdictional claims in published maps and institutional affiliations.

Copyright: (c) 2021 by the authors. Licensee MDPI, Basel, Switzerland. This article is an open access article distributed under the terms and conditions of the Creative Commons Attribution (CC BY) license (https:// creativecommons.org/licenses/by/ $4.0 /)$.

\begin{abstract}
Autism spectrum disorder (ASD) is characterized by a fundamental change in selfawareness including seemingly paradoxical features like increased ego-centeredness and weakened self-referentiality. What is the neural basis of this so-called "self-paradox"? Conducting a metaanalytic review of fMRI rest and task studies, we show that ASD exhibits consistent hypofunction in anterior and posterior midline regions of the default-mode network (DMN) in both rest and task with decreased self-non-self differentiation. Relying on a multilayered nested hierarchical model of self, as recently established (Qin et al. 2020), we propose that ASD subjects cannot access the most upper layer of their self, the DMN-based mental self-they are locked-out of their own DMN and its mental self. This, in turn, results in strong weakening of their self-referentiality with decreases in both self-awareness and self-other distinction. Moreover, this blocks the extension of non-DMN cortical and subcortical regions at the lower layers of the physical self to the DMN-based upper layer of the mental self, including self-other distinction. The ASD subjects remain stuck and restricted to their intero- and exteroceptive selves as manifested in a relative increase in ego-centeredness (as compared to self-referentiality). This amounts to what we describe as "Hierarchical Model of Autistic Self" (HAS), which, characterizing the autistic self in hierarchical and spatiotemporal terms, aligns well with and extends current theories of ASD including predictive coding and weak central coherence.
\end{abstract}

Keywords: mental-self; self-reference; autism spectrum disorder; default-mode network; predictive coding; weaken central coherence; theory of mind

\section{Introduction}

Autism spectrum disorder (ASD) is a complex psychiatric condition that is characterized by multiple symptoms. Cognitive symptoms like changes in autobiographical/episodic memory [1-4] are coupled with deficits in social cognition as in theory of mind [5-7], affective changes including emotion, empathy, and facial expression [8-10], hypersystemizing [11], motor symptoms like difficulty of action imitation [12-14], stereotypies and repetitions [15-17], and multimodal sensory integration [18-22]. Yet, on a deeper level beneath the various functions, an altered sense of self, i.e., self-awareness, has been described and is a key disturbance of autism [23].

In their original descriptions of autism, Kanner (1943) and Asperger (1944) point out a fundamental or basic disturbance of self: the self in ASD is only himself and selfsufficient [24] and feels neither an integral part of the world nor stands in a lively dynamic relationship with its environment [25]. More recently, Lombardo and Baron-Cohen (2010, 2011) highlighted what they describe as "paradox of self" in ASD [23,26] (see also [27-29]). On the one hand, the autistic self is highly centered on itself, showing an abnormally high degree of ego-centeredness as manifest in social isolation and loneliness, inability to read the emotions, feelings, and facial expressions of others [30-32], and major deficits in social cognition like theory of mind [5-7]. Such high ego-centeredness is, on the other hand, contrasted by weak self-referentiality with decreased use of " $\mathrm{I}$ " in language [33-35], no 
mention of own internal states, e.g., own emotion [10,36,37], own theory of mind [27,38,39], changes in time processing like duration estimation of shorter and longer time intervals as deficits in connecting different time points [40-42], decreased introspection [43,44], decrease in interoception [45-47], and reduced autobiographical memory [1-4] (see though Markram and Markram, 2012 [48], as well as Lind et al., 2020 [49]).

How is it possible that seemingly two contradictory features like increased egocenteredness and decreased self-referentiality can co-occur within one and the same person's self? Lombardo and Baron-Cohen (2010) assume a shared deficit in the neural circuitry that encodes self-representation, including self-other distinction and self-other awareness [26]. Various imaging studies, most often using fMRI, investigated self-reference in ASD. They observed changes in various anterior and posterior regions of the defaultmode network (DMN) and outside the DMN during self-referential tasks (see below). At the same time, resting state abnormalities could also be observed in anterior and posterior DMN (and also non-DMN) of ASD, which again showed major changes in DMN (see for recent review Lau et al., 2020 [50] and below). Given that various findings in healthy subjects indicate neural overlap of self and DMN resting state [51-56], one may assume a close relationship of resting state and self-specific task-related changes in DMN of ASD. The goal of the present paper is to review recent fMRI findings in ASD during both rest and self-referential task states in order to reconcile the seemingly features of increased ego-centeredness and decreased self-referentiality.

A recent meta-analytic study on the self in healthy subjects suggests a multilayered nested hierarchical model of self with interoceptive self, exteroceptive self, and mental self: neural correlates range from subcortical regions and insula (interoceptive self) over medial prefrontal cortex and temporo-parietal junction (TPJ) (exteroceptive self) to anterior and posterior DMN (mental self) [57,58]. Following such nested neural hierarchy of self, we propose that DMN hypofunction in both rest and task states (decreased/absent selfnon-self differentiation) renders it impossible for ASD subjects to access the most upper layer of their self, the mental self. This results in the weakening of their mental self with decreases in both self-referentiality and self-other awareness-they are locked-out of their mental self, including its self-other distinction. While, at the same time, they remain restricted to the lower layers of the intero- and exteroceptive self as mediated by non-DMN and subcortical regions-this is manifested in increased ego-centeredness. We conclude that DMN hypofunction in ASD disrupts the neural hierarchy of self as it blocks the mental self, i.e., it is locked-out, which weakens self-referentiality and, at the same time, (relatively) increases the lower layers of the intero- and exteroceptive self, i.e., increased ego-centeredness. Following these meta-analytic observations, we postulate a novel model of self in ASD, a "Hierarchical Model of Autistic Self" (HAS).

\section{Materials and Methods}

Studies included in this review were collected from the database PubMed with a time frame up to October 2020. The procedure included two different stages: collecting neural studies with self-relative tasks and resting state fMRI studies. Due to the heterogeneity of studies in terms of subject, measures, and method as well as the breath of data we included, we refrained from quantitative meta-analysis and focused on narrative review.

\subsection{Collecting Neural Studies with Self-Relative Tasks}

In this stage, fMRI studies using physical or psychological self-relative tasks were searched. The physical self-relative tasks included heartbeat, own-face/body recognition, agency, ownership of body or objects, and self-initiated motion. For these tasks, search terms used were "heartbeat", "own face", "self-face", "own body", "self-body", "ownership", "agency", and "executed action". The psychological tasks covered own-name recognition, self-emotion processing, autobiographical memory, trait adjective judgement, self-relevance sentence judgment, and self judgement in other complex tasks (i.e., decision making or pseudo-interactive joke). Search terms for these tasks were "self-name", "own- 
name", "self-reference", "self", "self-emotion", "autobiographical memory", and "episodic memory". All the search terms were combined with "autism" and "fMRI" to included temporal and functional neural studies on ASD.

A total of 324 results for fMRI were obtained with the initial search. Then, the results were screened by reviewing the title and abstract carefully and, if necessary, the whole paper was read through. Only studies that met the following criteria were include for further analysis: (a) fMRI studies; (b) using at least one of the physical self-relative tasks or psychological self-relative tasks; (c) including both individuals with ASD and TD group as participants. Those studies with narrative-qualitative reviews and meta-analysis were excluded.

Finally, only $19 \mathrm{fMRI}$ studies on this topic were included. With intensive reading, we extracted main information including demographic characteristic of participants (i.e., age bracket), self-relative tasks, and abnormal activity of individuals with ASD contrasted to TD group for fMRI studies (Table 1).

Table 1. Characteristics and main findings of fMRI studies with self-relative tasks in individuals with ASD.

\begin{tabular}{|c|c|c|c|c|}
\hline $\mathbf{N}$ & Authors & Participants & Stimulus & Neural Activation and Functional Connectivity \\
\hline 1 & Sumiya et al., 2020 & Adults $(\mathrm{N}=31)$ & $\begin{array}{l}\text { pseudo-interactive joke } \\
\text { task (self-relevant } \\
\text { social reward) }\end{array}$ & ASD < TD: arMPFC in Self vs. Baseline \\
\hline 2 & Lai et al., 2019 & $\begin{array}{l}\text { Adults }(\text { Male }=29 ; \\
\text { Female }=28)\end{array}$ & $\begin{array}{l}\text { adjective personality } \\
\text { traits (mentalizing } \\
\text { vs. physical) }\end{array}$ & $\begin{array}{l}\text { ASD }<\text { TD (males), but ASD = TD (females): vMPFC } \\
\text { in self vs. others } \\
\text { ASD }<\text { TD (males), but ASD = TD (females): right TPJ } \\
\text { in mentalizing vs. physical tasks }\end{array}$ \\
\hline 3 & Cynan et al., 2019 & Adults $(\mathrm{N}=15)$ & $\begin{array}{l}\text { Adjective personality } \\
\text { traits (past self, present } \\
\text { self; close other) }\end{array}$ & $\begin{array}{l}\text { ASD > TD: bilateral STG/TPJ, right Ins, PCC and left } \\
\text { MTG in past-self vs. close other } \\
\text { ASD = TD: bilateral STG/TPJ, right Ins, PCC and left } \\
\text { MTG in present self vs. close other }\end{array}$ \\
\hline 4 & $\begin{array}{l}\text { Hashimoto } \\
\text { et al., } 2017\end{array}$ & Adults $(\mathrm{N}=26)$ & $\begin{array}{l}\text { Adjective personality } \\
\text { traits (first vs. } \\
\text { third perspective) }\end{array}$ & $\begin{array}{l}\text { ASD < TD (in first-perspective): left TPJ/IPL in self } \\
\text { vs. other } \\
\text { ASD < TD: FC between left IFG and bilateral FPC in } \\
\text { third vs. first perspective }\end{array}$ \\
\hline 5 & Kana et al., 2017 & Adults $(\mathrm{N}=15)$ & $\begin{array}{l}\text { Adjective personality } \\
\text { traits (self, teachers, } \\
\text { and letter) }\end{array}$ & $\begin{array}{l}\text { ASD < TD: left IFG and left IPL in self vs. letter; THA, } \\
\text { caudate, CRE and cuneus in self vs. teacher; } \\
\text { ASD = TD: MPFC in self vs. teacher } \\
\text { ASD < TD: FC between right ACC and bilateral IFG, } \\
\text { right MTG, and left-putamen; left ACC and left IFG } \\
\text { and CER during self-processing. }\end{array}$ \\
\hline 6 & Pfeifer et al., 2013 & $\begin{array}{l}\text { Children and } \\
\text { adolescent }(\mathrm{N}=18)\end{array}$ & $\begin{array}{l}\text { Adjective personality } \\
\text { traits (social } \\
\text { vs. academic) }\end{array}$ & $\begin{array}{l}\text { ASD < TD: vMPFC, MCC and left AI in self } \\
\text { vs. others; } \\
\text { ASD = TD (youth): MPPC (PCUN, PCC, and RSC) in } \\
\text { self vs. other }\end{array}$ \\
\hline 7 & $\begin{array}{l}\text { Lombardo } \\
\text { et al., } 2009\end{array}$ & Adults $(\mathrm{N}=29)$ & $\begin{array}{l}\text { Adjective personality } \\
\text { traits (mental } \\
\text { vs. physical) }\end{array}$ & $\begin{array}{l}\text { ASD < TD: MCC; ASD = TD: vMPFC in self vs. other } \\
\text { ASD < TD: FC between vMPFC and PSC, frontal } \\
\text { operculum/VPMC in self vs. other }\end{array}$ \\
\hline 8 & $\begin{array}{l}\text { Kennedy \& } \\
\text { Courchesne, } 2008\end{array}$ & Adults $(\mathrm{N}=13)$ & $\begin{array}{l}\text { Self-personality traits } \\
\text { (internal vs. external) }\end{array}$ & $\begin{array}{l}\text { ASD < TD: vMPFC/vACC in Self vs. others } \\
\text { ASD = TD: dMPFC, left ANG, and RSC/PCC in } \\
\text { others vs. self }\end{array}$ \\
\hline 9 & Chiu et al., 2008 & $\begin{array}{l}\text { Adolescents } \\
(\mathrm{N}=12)\end{array}$ & $\begin{array}{l}\text { multitrust play game } \\
\text { (self vs. other decision) }\end{array}$ & ASD < TD: MCC during making own decision \\
\hline 10 & Morita et al., 2016 & Adults $(\mathrm{N}=14)$ & $\begin{array}{l}\text { Emotion processing } \\
\text { (embarrassment) in } \\
\text { self-face recognition }\end{array}$ & $\begin{array}{l}\text { ASD < TD: right OC including IOG in self vs. other } \\
\text { ASD = TD: right IFG and Ins in self vs. other } \\
\text { ASD < TD: FC between caudal ACC and MPFC in } \\
\text { observation vs. unobserved; }\end{array}$ \\
\hline 11 & Mortia et al., 2012 & Adults $(\mathrm{N}=15)$ & $\begin{array}{l}\text { Emotion processing } \\
\text { (embarrassment) in } \\
\text { self-face recognition }\end{array}$ & $\begin{array}{l}\text { For ASD, self }>\text { others in bilateral mid-IFG and THA, } \\
\text { the left STG, right Ins, and ACC. } \\
\text { ASD < TD: PCC in self vs. others; right Ins for } \\
\text { both condition. }\end{array}$ \\
\hline
\end{tabular}


Table 1. Cont.

\begin{tabular}{|c|c|c|c|c|}
\hline $\mathbf{N}$ & Authors & Participants & Stimulus & Neural Activation and Functional Connectivity \\
\hline 12 & Silani et al., 2008 & Adults $(\mathrm{N}=14)$ & $\begin{array}{l}\text { Self-emotion awareness } \\
\text { (internal vs. external) }\end{array}$ & $\begin{array}{l}\text { ASD < TD: MPFC, right ACC, left PCUN, left TP and } \\
\text { CRE in internal vs. external awareness; left AI in } \\
\text { viewing unpleasant vs. neutral pictures. } \\
\text { ASD > TD: right HC in relational vs. item-specific }\end{array}$ \\
\hline 13 & $\begin{array}{l}\text { Hogeveen et al., } \\
2020\end{array}$ & $\begin{array}{l}\text { Adolescent and } \\
\text { Young adults } \\
(\mathrm{N}=47)\end{array}$ & $\begin{array}{l}\text { Episodic memory } \\
\text { encoding tasks }\end{array}$ & $\begin{array}{l}\text { ASD = TD: bilateral MTL in Relational } \\
\text { vs. item-specific } \\
\text { ASD < TD: FC between right PHC and left HC; right } \\
\text { PHC and left PCC; but ASD = TD between MTL and } \\
\text { whole brain. }\end{array}$ \\
\hline 14 & Cooper et al., 2017 & Adults $(\mathrm{N}=21)$ & Episodic memory tasks & $\begin{array}{l}\text { ASD = TD: HC, PPC, MPFC in both encoding and } \\
\text { retrieval vs. baseline. ASD < TD: LPFC in retrieval } \\
\text { vs. baseline; } \\
\text { ASD =TD: strength node of LPFC and PCC during } \\
\text { retrieval phase; ASD < TD: strength node of HC, FC } \\
\text { between HC-FPCN and HC-DMN during retrieval } \\
\text { phase, but no group difference during decoding. } \\
\text { HC and MPFC activity increased for both ASD and } \\
\text { TD in successful vs. unsuccessful retrieval; no group } \\
\text { difference in correlation between HC, MPFC, and } \\
\text { PCC activation and successful retrieval/ } \\
\text { retrieval precision. }\end{array}$ \\
\hline 15 & Gaigg et al., 2015 & Adults $(\mathrm{N}=13)$ & $\begin{array}{l}\text { Episodic memory with } \\
\text { words triplet task }\end{array}$ & $\begin{array}{l}\text { ASD > TD: left IFG; ASD < TD: left posterior HC in } \\
\text { successful encoding vs. baseline. } \\
\text { ASD = TD: bilateral MTL in Remember vs. Known } \\
\text { ASD < TD: right IFG, left MFG, right IPL in }\end{array}$ \\
\hline 16 & Greimel et al.2012 & $\begin{array}{l}\text { Children and } \\
\text { Adolescents } \\
(\mathrm{N}=13)\end{array}$ & $\begin{array}{l}\text { Episodic memory } \\
\text { (social vs. non-social) }\end{array}$ & $\begin{array}{l}\text { Recol-NoRecol Face (social), bilateral SMG/dMPFC } \\
\text { in Recol-NoRecol House (non-social). } \\
\text { ASD = TD in AMG, FFG, or HC activation in } \\
\text { Recol-NoRecol House (non-social) }\end{array}$ \\
\hline 17 & Failla et al., 2020 & Adults $(\mathrm{N}=46)$ & Heart beating counting & ASD = TD: bilateral Ins. \\
\hline 18 & $\begin{array}{l}\text { Okamoto } \\
\text { et al., } 2018\end{array}$ & Adults $(\mathrm{N}=18)$ & $\begin{array}{l}\text { Self and other } \\
\text { hand pictures }\end{array}$ & $\begin{array}{l}\text { ASD < TD: MPFC (including left MFG and ACC) in } \\
\text { third vs. first perspective; }\end{array}$ \\
\hline 19 & Uddin et al., 2008 & Children $(\mathrm{N}=12)$ & Self-face & $\begin{array}{l}\text { ASD = TD: right IFG, MFG, PrCG, ANG, SPL, } \\
\text { bilateral LOC, and FFG in self-face. }\end{array}$ \\
\hline
\end{tabular}

Note: MPFC-ventral medial prefrontal cortex; vMPFC—ventral medial prefrontal cortex; arMPFC—anterior rostral medial prefrontal cortex; dMPFC—dorsal medial prefrontal cortex; LPFC—lateral prefrontal cortex; IFC/IFG—inferior frontal cortex/inferior frontal gyrus; MFG—-middle frontal gyrus; FPC—-frontopolar cortex; VPMC—ventral premotor cortex; IPL—inferior parietal lobule; MPPC—-medial posterior parietal cortex; PPC—-posterior parietal cortex; SPL—superial parietal lobule; PSC—primary somatosensory cortex; PrCG—precentral gyrus; OC—occipital cortex; IOG—inferior occipital gyrus; LOTC—lateral occipitotemporal cortex; LOC-lateral occipital cortex; TPJ—-temporo-parietal junctions; STG—superior temporal gyrus; MTG/MTL—middle temporal gyrus/lobe; TP—temporal Pole; FFG—-fusiform gyrus; ACC—anterior cingulate cortex; PCC/PCG—-posterior cingulate cortex/gyrus; MCC—middle cingulate cortex; PCUN-precuneus; RSC-retrosplenial cortex; ANG—angular gyrus; AI-anterior insular; Ins-Insular; HC-hippocampus; PHC-parahippocampal cortex; AMG-amygdala; THA-thalamus; CRE-cerebellum; SMG-superior medial gyrus; FPCN—fronto-parietal task control network (including lateral prefrontal and inferior parietal cortices); DMN—default-mode network; FC-functional connectivity.

\subsection{Collecting Resting-States fMRI Studies}

To verify the hypothesis that abnormal neural activity of individuals with ASD during self-relative tasks could be mapped into the neural activation during resting states, resting state fMRI studies were searched in this stage with the following terms: "autism", "resting sates", and "fMRI" in PubMed.

After initial research, 472 results were obtained. A screening procedure as a last stage was conducted to assess whether the studies (a) were resting state fMRI studies; (b) included both individuals with ASD and TD group as participants; (3) reported neural activation or functional connectivity of any brain regions mentioned in results of self-relative task reviewing parts. Those studies with narrative-qualitative reviews and meta-analysis were also excluded. 
Finally, 97 studies were gained, from which the demographic characteristic of participants (i.e., age bracket), fMRI data processing methods, and abnormal neural activation or functional connectivity of individuals with ASD contrasted to TD group were extrapolated (Table 2).

Table 2. Characteristics of resting state fMRI studies in individuals with ASD.

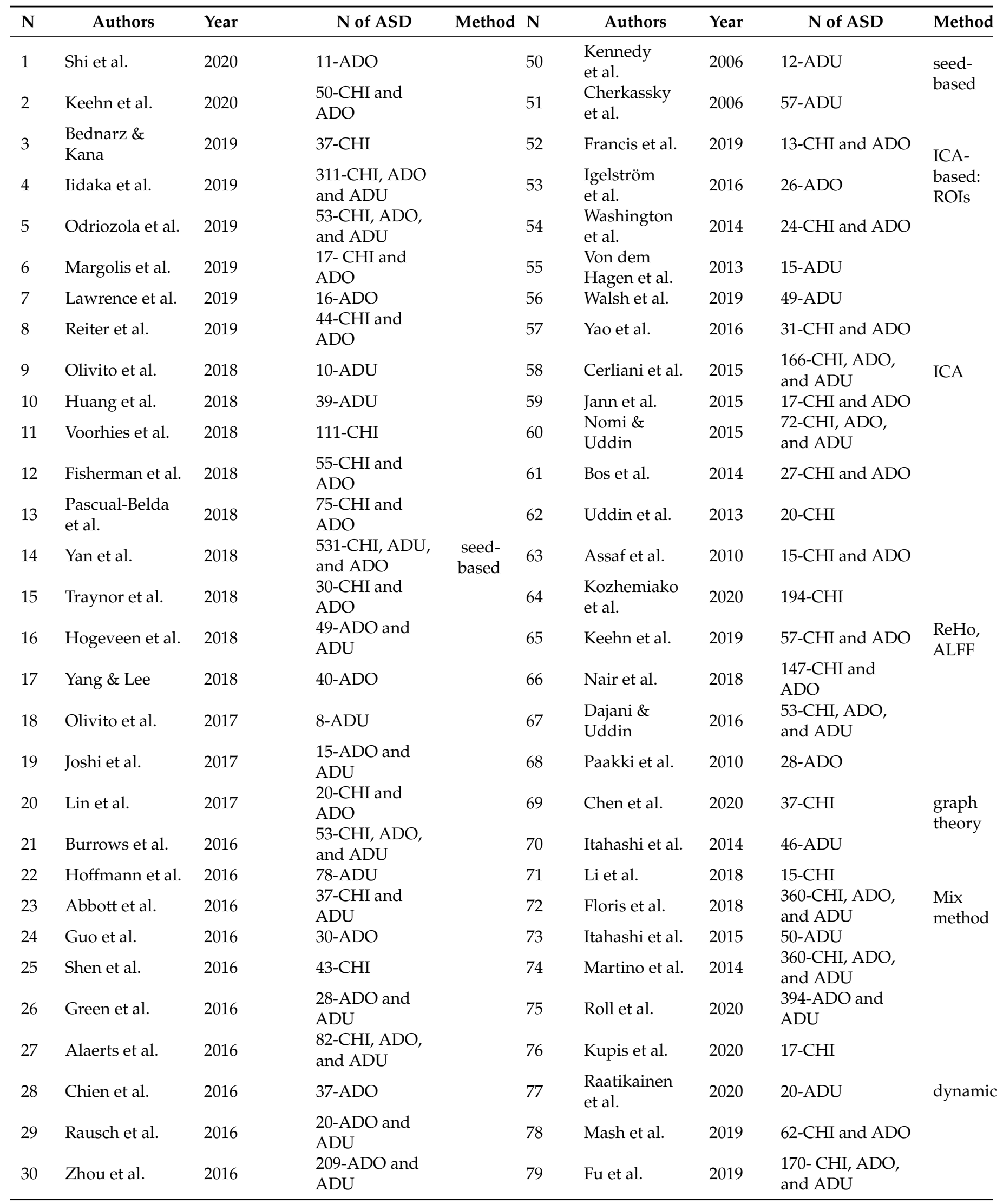


Table 2. Cont.

\begin{tabular}{|c|c|c|c|c|c|c|c|c|c|}
\hline $\mathbf{N}$ & Authors & Year & $\mathrm{N}$ of ASD & Method & $\mathbf{N}$ & Authors & Year & $\mathrm{N}$ of ASD & Method \\
\hline 31 & Kleinhans et al. & 2016 & $\begin{array}{l}\text { 25-ADO and } \\
\text { ADU }\end{array}$ & & 80 & He et al. & 2018 & 28-CHI & \multirow{19}{*}{$\begin{array}{l}\text { degree } \\
\text { cen- } \\
\text { trality }\end{array}$} \\
\hline 32 & $\begin{array}{l}\text { Farrant \& } \\
\text { Uddin }\end{array}$ & 2016 & $\begin{array}{l}\text { 20-CHI and } \\
\text { 15-ADU }\end{array}$ & & 81 & Guo et al. & 2018 & $\begin{array}{l}\text { 209-ADO and } \\
\text { ADU }\end{array}$ & \\
\hline 33 & Khan et al. & 2015 & 28-CHI and ADO & & 82 & $\begin{array}{l}\text { Besseling } \\
\text { et al. }\end{array}$ & 2018 & $\begin{array}{l}\text { 125-CHI, ADU, } \\
\text { and ADO }\end{array}$ & \\
\hline 34 & $\begin{array}{l}\text { Doyle-Thomas } \\
\text { et al. }\end{array}$ & 2015 & 58-CHI and ADO & & 83 & $\begin{array}{l}\text { Falahpour } \\
\text { et al. }\end{array}$ & 2016 & $\begin{array}{l}\text { 76-CHI, ADO, } \\
\text { and ADU }\end{array}$ & \\
\hline 35 & Fisherman et al. & 2015 & 35-CHI and ADO & & 84 & Holiga et al. & 2019 & $\begin{array}{l}\text { 841-CHI, ADO, } \\
\text { and ADU }\end{array}$ & \\
\hline 36 & Yerys et al. & 2015 & 22-CHI & & 85 & Lee et al. & 2017 & $\begin{array}{l}\text { 329-CHI, ADO, } \\
\text { and ADU }\end{array}$ & \\
\hline 37 & Nair et al. & 2015 & 37-CHI and ADO & & 86 & Long et al. & 2016 & $\begin{array}{l}\text { 64-CHI, ADO, } \\
\text { and ADU }\end{array}$ & \\
\hline 38 & Chien et al. & 2015 & 40-CHI and ADO & & 87 & $\begin{array}{l}\text { Di Martino } \\
\text { et al. }\end{array}$ & 2013 & $56-\mathrm{CHI}$ & \\
\hline 39 & Fisherman et al. & 2014 & 40-ADO & & 88 & $\begin{array}{l}\text { Oldehinkel } \\
\text { et al. }\end{array}$ & 2019 & $\begin{array}{l}\text { 265-CHI, ADO, } \\
\text { and ADU }\end{array}$ & \\
\hline 40 & Lynch et al. & 2013 & 20-CHI & & 89 & $\begin{array}{l}\text { Anteraper } \\
\text { et al. }\end{array}$ & 2019 & 24-ADU & \\
\hline 41 & Delmonte et al. & 2013 & $\begin{array}{l}\text { 28-ADO and } \\
\text { ADU }\end{array}$ & & 90 & Chen et al. & 2018 & 29-CHI & \\
\hline 42 & $\begin{array}{l}\text { Murdaugh } \\
\text { et al. }\end{array}$ & 2012 & 13-ADU & & 91 & Cheng et al. & 2017 & $\begin{array}{l}\text { 394-CHI, ADO, } \\
\text { and ADU }\end{array}$ & \\
\hline 43 & Wiggins et al. & 2011 & 39-CHI and ADO & & 92 & Duan et al. & 2017 & 91-ADO & \\
\hline 44 & Ebisch et al. & 2011 & 14-CHI and ADO & & 93 & Lee et al. & 2016 & $\begin{array}{l}\text { 458-CHI, ADO, } \\
\text { and ADU }\end{array}$ & \\
\hline 45 & $\begin{array}{l}\text { Di Martino } \\
\text { et al. }\end{array}$ & 2011 & 20-CHI & & 94 & Cheng et al. & 2015 & 418-ADO & \\
\hline 46 & Weng et al. & 2010 & 16-ADO & & 95 & Tyszka et al. & 2014 & \multirow{4}{*}{$\begin{array}{l}\text { 19-ADU } \\
31-A D O \text { and } \\
\text { ADU } \\
40-A D O \text { and } \\
\text { ADU }\end{array}$} & \\
\hline 47 & Monk et al. & 2009 & 12-ADU & & 96 & Gotts et al. & 2012 & & \\
\hline 48 & $\begin{array}{l}\text { Kennedy \& } \\
\text { Courchesne (a) }\end{array}$ & $2008^{a}$ & 12-ADU & & 97 & $\begin{array}{l}\text { Anderson } \\
\text { et al. }\end{array}$ & 2011 & & \\
\hline 49 & $\begin{array}{l}\text { Kennedy \& } \\
\text { Courchesne (b) }\end{array}$ & $2008^{b}$ & 13-ADU & & & & & & \\
\hline
\end{tabular}

Note: CHI-children; ADO-adolescents; ADU—adults; ReHo-regional homogeneity; ICA—independent component analysis; ALFF-amplitude of low-frequency fluctuation; Mix method-including at least two methods of ReHo, ALFF, DC, ICA, or graph theory.

With these two reviewing parts, we were able to compare the neural activity during self-relative tasks to resting state fMRI and then make hypotheses about the changes in activity from task to rest and how they can be intrinsically related.

\section{Results}

\subsection{Task fMRI in ASD: Task-Related Neural Activity and Functional Connectivity during Self}

A total of 19 studies evaluated the neural activity with self-specific tasks in individuals with ASD. Among these studies, 16 studies focused on the psychological self (7 studies with the self-reference task, 2 studies with social reward task, 3 studies with emotional task, and 4 studies with episodic memory task), while the other studies focused more on the physical self (1 study about heartbeat and 2 studies with self-body recognition task) (Table 1). Across these different tasks, decreased activation in DMN regions during self-specific tasks/stimuli was reported, with a particular emphasis on reduction in medial prefrontal cortex (MPFC) (including ventral medial prefrontal cortex (vMPFC) and dorsal medial prefrontal cortex (dMPFC)), anterior cingulate cortex (ACC), media cingulate cortex (MCC), and inferior parietal lobule (IPL) (Figure 1a-f). In contrast to the anterior midline regions, findings in posterior cingulate cortex (PCC)and precuneus (PCUN) are not as 
consistent among different studies and tasks: decreased activity was observed during the emotional recognition tasks in ASD, whereas they did not show any abnormalities in these regions during the self-reference task (Figure $1 \mathrm{~b}$ ).

In non-DMN regions, hypoactivity of cerebellum (CRE) and middle frontal gyrus (MFG) is reported for individuals with ASD compared to TD in a few studies (Figure 1c-f). Contradictory results were found for the activity of inferior frontal gyrus (IFG) (Figure 1c-f), TPJ (Figure 1c-f), insula, and hippocampus (HC) across different tasks (Figure 1g,h).

Few studies also evaluated the task-related deactivation of DMN in ASD. In anterior regions of DMN, individuals with ASD show either reduced deactivation (e.g., vMPFC, MPFC, and ACC) or "normal" levels of deactivation (e.g., ACC and dMPFC). Although one study reports reduced deactivation in PCC and PCUN in ASD, two studies could now show group difference in deactivation of PCC, PCUN, and retrosplenial cortex (RSC) (Figure 2a).

Finally, few studies investigated the functional connectivity among different brain regions during self-specific tasks. With the few results available, hypoconnectivity between DMN regions (e.g., vMPFC, ACC, and PCC) and non-DMN regions (e.g., IFG, medial temporal gyrus (MTG), CRE, putamen (Put), parahippocampal cortex (PHC), ventral premotor cortex (VPMC), and primary somatosensory cortex (PSC)), as well as within the DMN itself (e.g., MPFC-ACC) were reported (Figure 2b).

Taking together, unlike the inconsistent results of most of the non-DMN regions, individuals of ASD show decreased activity, i.e., amplitude or magnitude in DMN, especially in the anterior parts across different self-specific tasks, i.e., domain-general. Decreased self-specific activity in these regions is further supported by observations that individuals of ASD also exhibit reduced deactivation and hypoconnectivity within DNM and of DMN with non-DMN regions during various self-specific tasks.

\subsection{Resting State fMRI in ASD: Resting State Functional Connectivity (rsFC) within DMN}

The fMRI studies investigating rsFC in individuals with ASD highlight abnormal activity within DMN. Although few studies showed hyperconnectivity of dMPFC with RSC and right IPL, left temporal pole (TP) with RSC and PCC, a decrease in rsFC between anterior DMN (e.g., MPFC/vMPFC and ACC) and posterior DMN (e.g., PCC, PCUN, and IPL) is a consistent finding across various studies (Figure 3a,b). Within anterior DMN regions, hypoconnectivity among vMPFC, dMPFC, ACC, and bilateral TP was observed, with the exception of one of study that reported hyperconnectivity between the MPFC and ACC (Figure 3a,b). Within the posterior DMN regions, both hypoconnectivity and hyperconnectivity between PCC and PCUN, PCC and bilateral IPL, and PCUN and bilateral IPL has been observed by a few studies, while decreased rsFC was reported between RSC and PCC, PCUN in one study. When it comes to the whole-brain rsFC, both anterior and posterior DMN regions show decreased rsFC (with only one study showing increased rsFC in ACC and PCC) (Figure 3c).

Unlike the results of static rsFC, the few studies on dynamic rsFC show contradictory rsFC results between anterior DMN (vMPFC and ACC) and posterior DMN (PCC and PCUN) in ASD including weaker, equal, and stronger rsFC, respectively (Figure 4a). A few studies investigating the dynamic whole-brain rsFC of DMN also report contradictory results, with two studies showing increased rsFC and two studies reporting decreased rsFC for individuals with ASD. More consistent is a decrease of dynamic rsFC within anterior DMN (e.g., vMPFC, ACC, and TP) in ASD (Figure 4a).

Overall, individuals with ASD show decreased static rsFC between anterior DMN and posterior DMN as well as reduced whole-brain hypoconnectivity of the DMN. In contrast, results on dynamic rsFC are more inconsistent, though they consistently also show decreased variability in anterior DMN rsFC. 


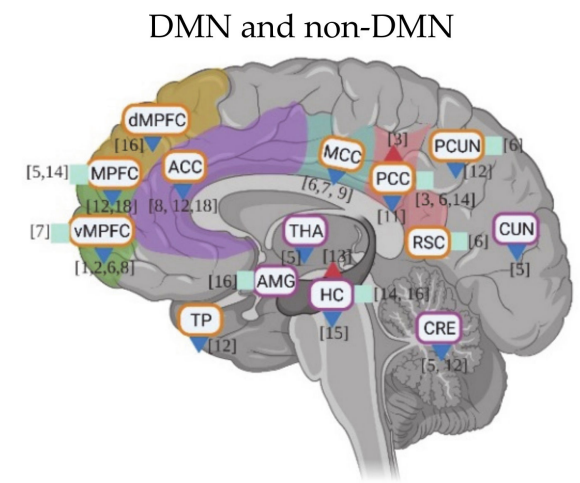

(a)

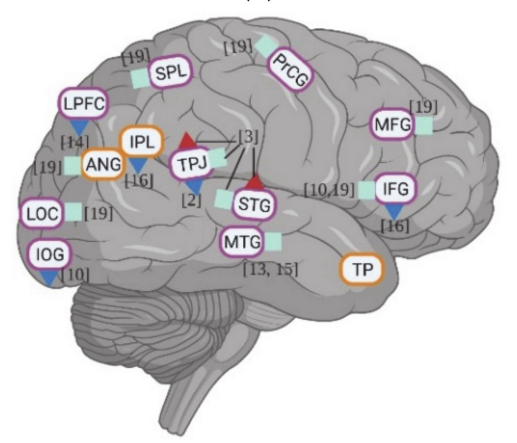

(c)

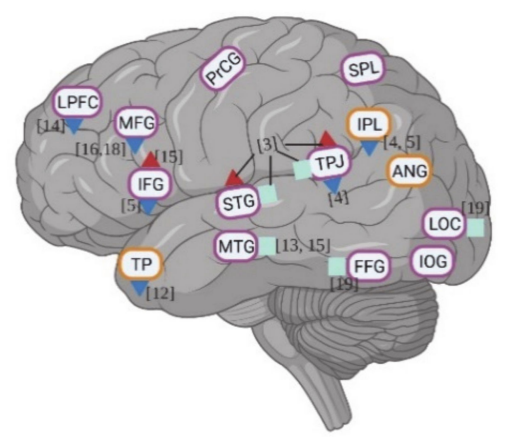

(e)

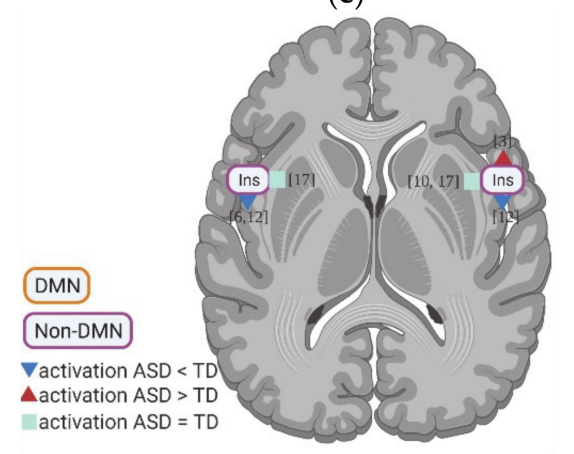

(g)

\section{Self vs. Non-self}

Difference self-specific task domain

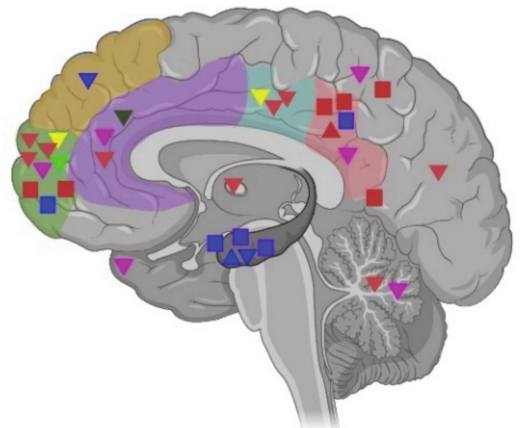

(b)

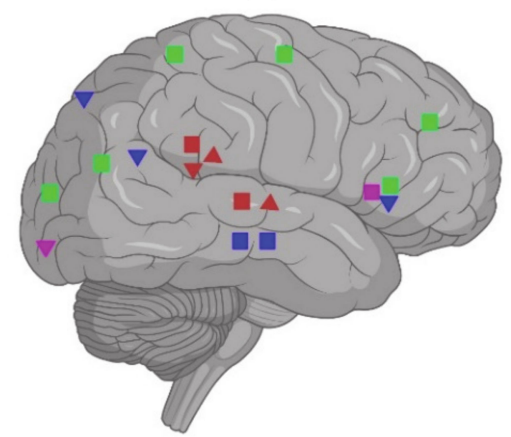

(d)

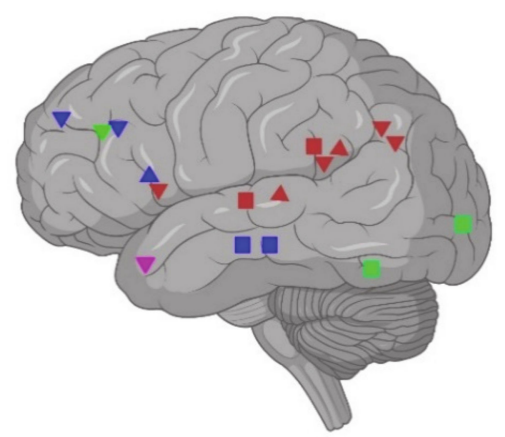

(f)

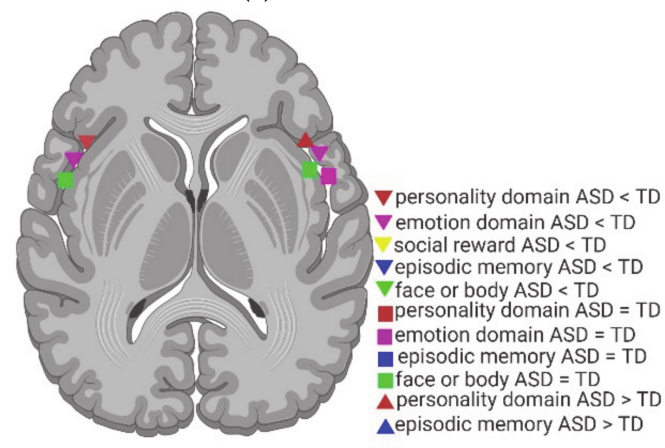

(h)

Figure 1. Activation of DMN and non-DMN regions for individuals with ASD compared to TD during self-specific tasks in different studies (left side) and different domains (right side): (a,b) DMN, subcortical regions and cerebellum (CRE); $(\mathbf{c}, \mathbf{d})$ related regions in right lateral hemisphere; (e,f) related regions in left lateral hemisphere; (g,h) insula (Ins). The numbers in the figure correspond to the study numbers in Table 1. 


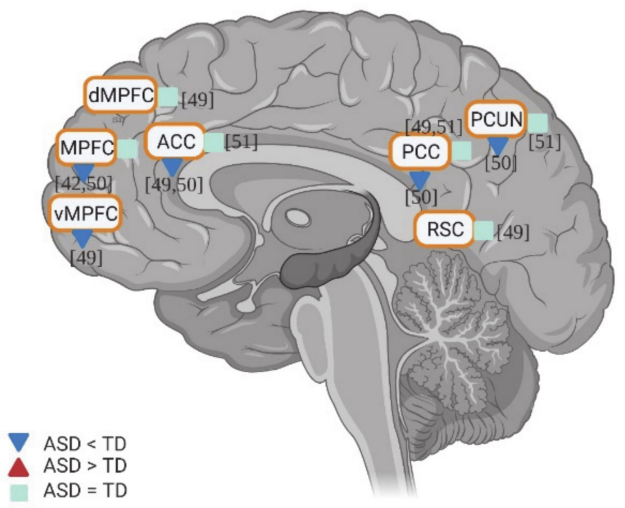

(a)

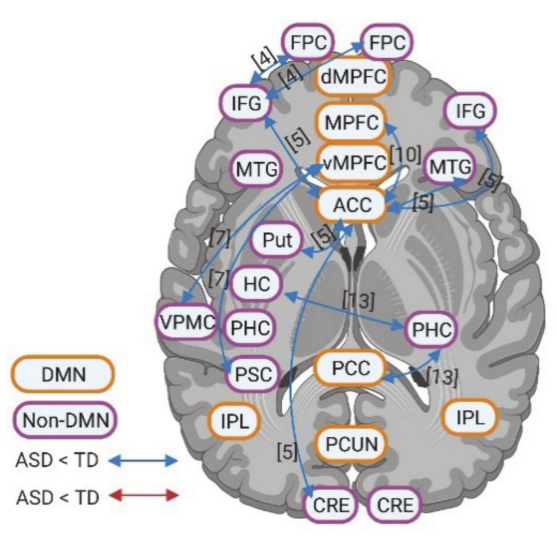

(b)

Figure 2. (a) Deactivation of DMN for individuals with ASD compared to TD during self-specific tasks in contrast with resting states. The numbers in the figure correspond to the study numbers in Table 2. (b) Functional connectivity within DMN and between DMN and non-DMN regions for individuals with ASD compared to TD during self-specific tasks. The numbers in figure correspond to the study numbers in Table 1.

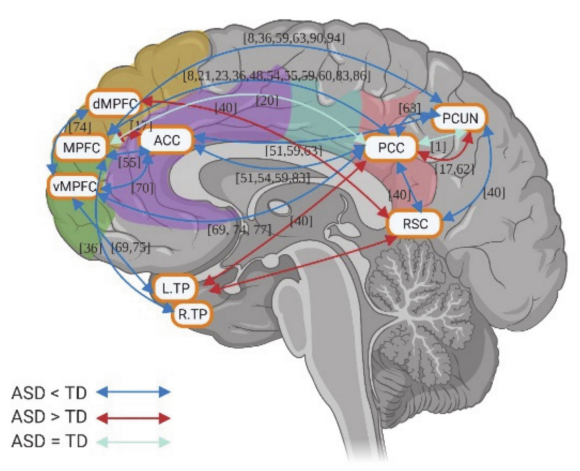

(a)

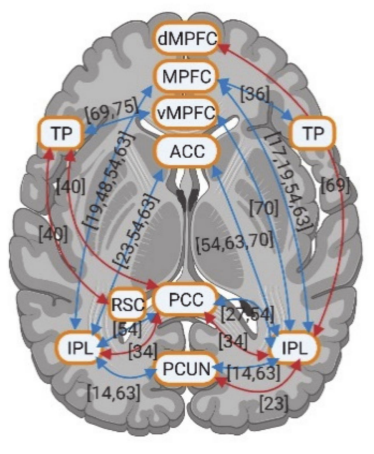

(b)

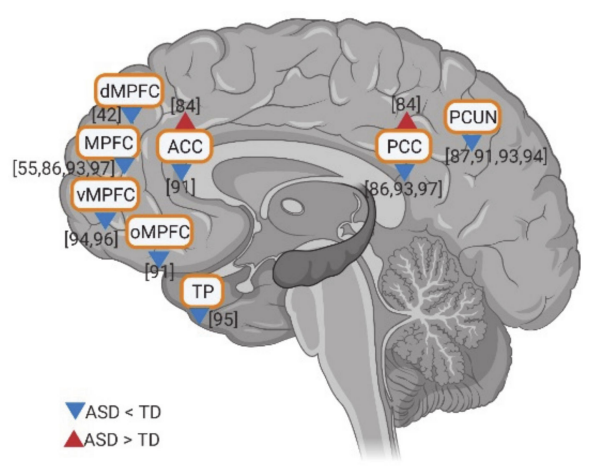

(c)

Figure 3. Inter-regional functional connectivity $(\mathbf{a}, \mathbf{b})$ and whole-brain resting state functional connectivity (c) of DMN for individuals with ASD compared to TD. The numbers in the figure correspond to the study numbers in Table 2.

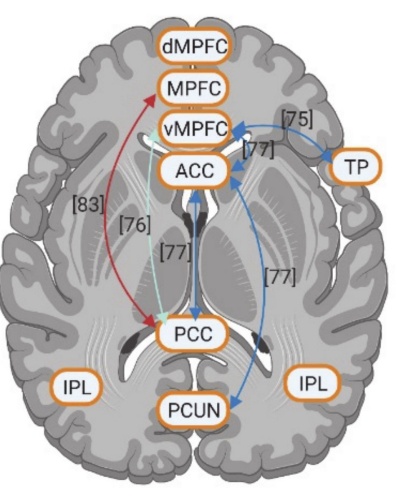

(a)

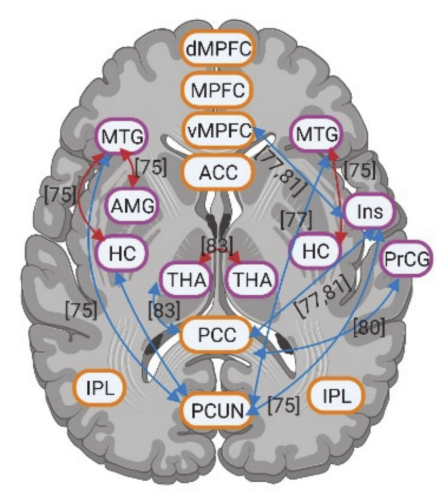

(b)

Figure 4. Dynamic functional connectivity between regions within DMN regions (a) as well as between DMN and non-DMN regions (b) for individuals with ASD compared to TD. The numbers in the figure correspond to the study numbers in Table 2. 


\subsection{Resting State fMRI in ASD: Resting State Functional Connectivity between DMN and Non-DMN}

The various resting state fMRI studies examined also underline altered rsFC between DMN and non-DMN regions in individuals with ASD. In the lateral frontal regions (Figure 5a,b), superior frontal gyrus (SFG) especially in the right hemisphere is reported to have altered rsFC with posterior DMN (e.g., PCC, PCUN, and IPL) with a tendency towards hypoconnectivity: six studies report decreased rsFC, while three studies observed increased rsFC. IFG showed hyperconnectivity with posterior DMN (e.g., PCC, PCUN, and RSC), and MFG also exhibited predominant increased rsFC with posterior DMN: three studies show increased rsFC and two studies report decreased rsFC. Unlike posterior DMN, there are less studies investigating the rsFC between anterior DMN and lateral frontal regions. For IFG, weaker rsFC with anterior DNM was found in two studies while stronger rsFC was found in one study. For SFG, both decreased and increased rsFC with anterior DMN were found in one study. In temporal lobe (TL) (Figure 5a,b), studies reported hyperconnectivity with PCC when considering TL as whole region. However, different subregions of temporal lobe showed distinct rsFC patterns with posterior DMN. Hypoconnectivity was observed for superior temporal gyrus (STG) with PCUN and IPL, MTG with PCUN and IPL, and inferior temporal gyrus (ITG) with PCC, whereas hyperconnectivity was reported for fusiform gyrus (FFG) with PCC. As opposed to the posterior DMN, the anterior DMN, especially the MPFC/vMPFC, exhibits relatively consistent hypoconnectivity with temporal lobe subregions, including decreased $\mathrm{rsFC}$ for the whole $\mathrm{TL}$, a decrease in rsFC for STG, and weaker rsFC for MTG, but also sees increased rsFC MTG. There is also hypoconnectivity of TPJ with both anterior, i.e., MPFC, and posterior DMN, i.e., PCC, PCUN, and IPL (Figure 5c). Finally, bilateral insula was observed to have decreased rsFC with anterior DMN (MPFC and ACC) and increased rsFC with posterior DMN (PCC, RSC and IPL); there is also higher rsFC with PCUN (Figure 5c).

Compared to the static rsfMRI studies, dynamic rsfMRI studies showed relatively consistent weaker rsFC of DMN, especially the posterior DMN with cortical non-DMN regions, i.e., MTG, precentral gyrus (PrCG), and insula (Figure 4b).

In general, individuals with ASD showed decreased rsFC between SFG and posterior DMN regions as well as hypoconnectivity of STG, MTG, ITG, TPJ, and insular with both anterior and posterior DMN during resting states. Weaker dynamic rsFC of DMN with nonDMN regions was also found for individuals with ASD. However, they had predominant hyperconnectivity of IFG, MFG, and FFG with posterior DMN during resting states.

\subsection{Resting State fMRI in ASD: Subcortical-Cortical Resting State Functional Connectivity}

Subcortical regions also had changes in their rsFC with DMN. The amygdala (AMG) exhibits hypoconnectivity with both anterior (e.g., MPFC and ACC) and posterior DMN (e.g., PCC) for individuals with ASD; although some studies did not show any group difference (Figure 5e). Similar to AMG, HC shows weaker rsFC both with anterior (e.g., MPFC and ACC) and with posterior DMN (e.g., PCC and PCUN) with the exception of higher rsFC with MCC (Figure 5e). However, PHC exhibits decreased rsFC with anterior DMN whereas it showed increased rsFC with posterior DMN (e.g., PCC and RSC) (Figure 5e). Few studies focused on thalamus (THA) rsFC with DMN and showed contradictory results: two studies observed increased rsFC with ACC/orbital MPFC and PCC, while one reports decreased rsFC with MPFC, PCC, and PCUN (Figure 5d). Furthermore, the cerebellum was observed to have increased rsFC with MPFC and PCC, whereas it shows decreased rsFC with PCUN (Figure 5f). Finally, in contrast to the static rsfMRI studies, dynamic rsfMRI studies showed relatively consistent weaker rsFC of DMN, especially the posterior DMN with subcortical regions, i.e., HC and THA (Figure $4 b$ ).

In sum, AMG and HC show hypoconnectivity with both anterior and posterior DMN in static and dynamic rsFC. In contrast, the CRE exhibits predominant hyperconnectivity with DMN during resting states. The THA shows a contradictory rsFC pattern across the studies. 


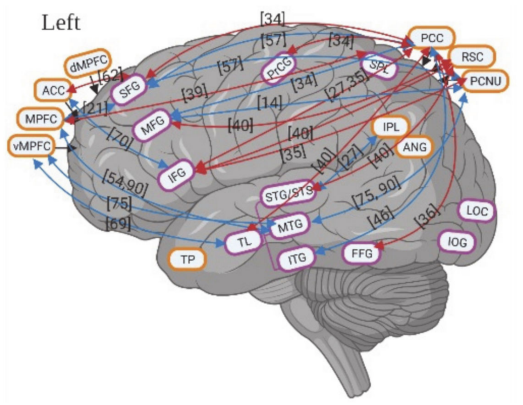

(a)

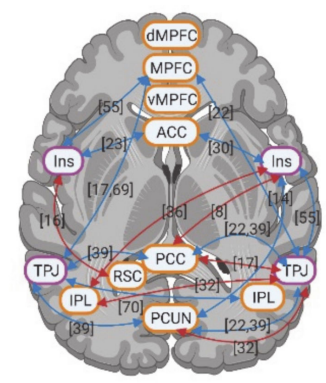

(c)

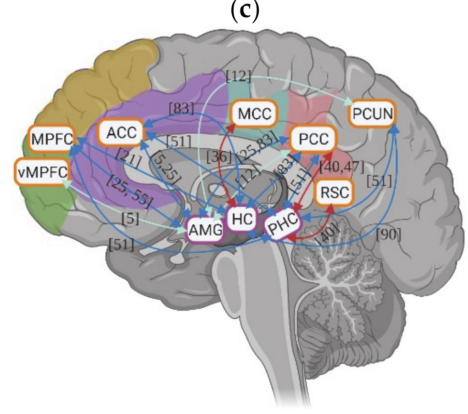

(e)

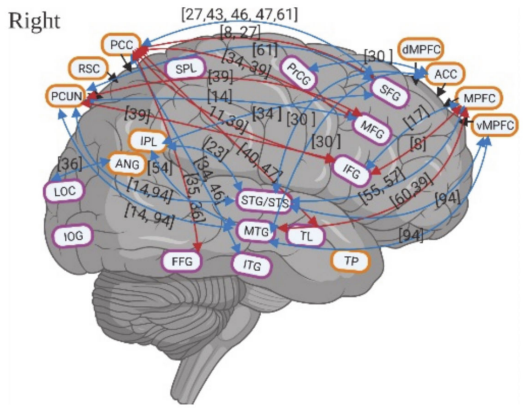

(b)

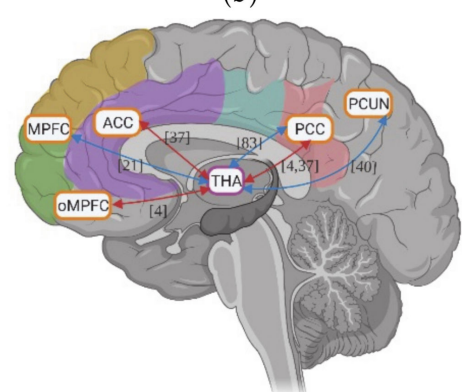

(d)

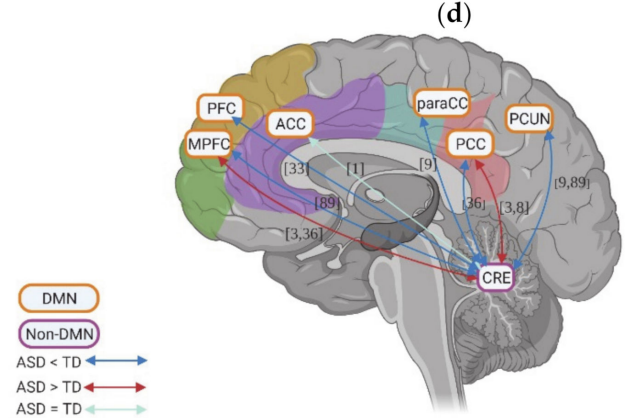

(f)

Figure 5. Functional connectivity between DMN and non-DMN regions for individuals with ASD compared to TD. In this figure, $(\mathbf{a}, \mathbf{b})$ shows the functional connectivity between DMN and non-DMN regions in left and right hemisphere; (c) shows functional connectivity between DMN and Insular (Ins), temporo-parietal junctions (TPJ); (d) shows the functional connectivity between thalamus (THA) and DMN; (e) shows the functional connectivity between DMN and amygdala (AMG), hippocampus cortex (HC), and parahippocampal cortex (PHC); (f) shows the functional connectivity between cerebellum (CRE) and DMN. The numbers in the figure correspond to the study numbers in Table 2.

\subsection{Resting State fMRI in ASD: ALFF and REHO in DMN Regions}

Few studies investigated the intraregional resting state activity using amplitude of lowfrequency fluctuations (ALFF) and regional homogeneity (ReHo), in individuals with ASD compared to TD controls. In these studies, relatively consistent results of the intraregional activity of the DMN were reported. Anterior DMN regions (e.g., MPFC, ACC, and TP) have reduced activity in ReHo. Meanwhile, although two studies reported hyperactivity in PCUN in ReHo, the posterior DMN regions (e.g., PCC and PCUN) show decreased activity in both ALFF and ReHo in ASD (Figure 6). In general, findings show decreased intraregional resting state activity in anterior and posterior DMN regions in ASD. 


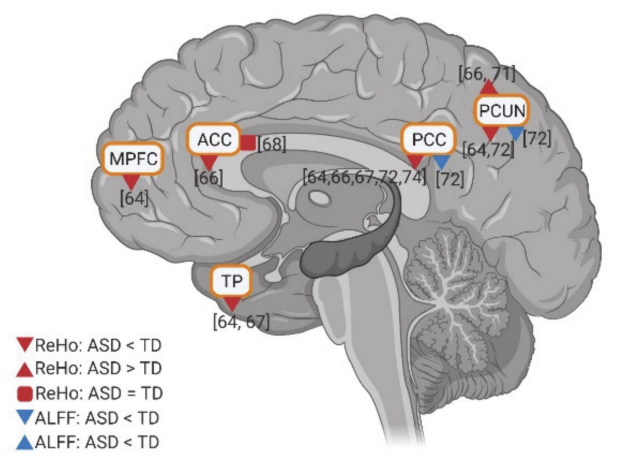

Figure 6. Intraregional resting state activity (ALFF and REHO) in DMN for individuals with ASD compared to TD. The numbers in the figure correspond to the study numbers in Table 2.

\section{Discussion}

How can increased ego-centeredness in ASD co-occur with weakened self-referentiality? Recent fMRI studies reveal decreased if not absent neural differentiation of self- and nonself-reference in anterior and posterior midline structures of the DMN. The same DMN regions also show decreased resting state connectivity among each other while, at the same time, being abnormally connected to non-DMN regions like lateral prefrontal, temporal, hippocampus/amygdala, and cerebellum.

Presupposing a neural hierarchical model of self, we propose that access to the mental self as DMN-based upper layer of self is blocked in ASD-this weakens self-referentiality including self-awareness and self-other distinction. That, in turn, shifts the focus to the lower layers of self, the intero- and exteroceptive self as mediated by non-DMN cortical and subcortical regions, resulting in the (relative) increase of ego-centeredness. Accordingly, the neural hierarchy of self is disrupted in ASD as its most upper layer, the DMN-based mental self, is hypofunctional and blocked-they are locked-out of their own mental self. The assumption of such "Hierarchical model of Autistic Self" (HAS) does not only explain the self-paradox but also aligns well and extends current theories of ASD like predictive coding and central coherence.

\subsection{Hypoactivity and -Connectivity within Midline DMN I-Weakening of Self-Referentiality or "Locked-Out of Their Own Mental Self"}

One of the most consistent observations in ASD is the lack of self-referentiality on both psychological and neural grounds. Various facets of the so-called psychological self [59] like use of the term "I" [33-35], mention of internal states [27,38,39], reference to own emotions and feelings [10,36,37], introspection [43,44], and episodic memory [1-4] are decreased in ASD $[23,26,29,60]$. Neuronally, the various task studies on self-specificity show decreased self-non-self differentiation in anterior and posterior midline structures of the DMN holding across different modalities and domains, i.e., supra-modal and domain-general. Given the close link of midline DMN and self-referentiality in healthy subjects [54,58,61-65], reduced midline DMN-based self-non-self differentiation is rather likely to be related to the decreased self-referentiality and hence the weakened mental self in ASD.

In addition to its reduced task-related activity during self-reference, midline DMN activity is also less connected between its anterior and posterior midline regions, as shown in both task and rest functional connectivity. Especially, reduced anterior-posterior midline DMN resting state functional connectivity is an often-observed finding [66-72] and confirmed in recent quantitative meta-analysis [50]. This suggests that even in the resting state, self-reference of especially internally oriented inputs and cognition is also impaired in ASD. Specifically, based on healthy subject data $[54,56,58,65,73-75]$, we assume that the autistic self is already altered during the more internally oriented cognition dominating in the resting state; this is carried over to subsequent task states where more externally oriented cognition dominates, such as during tasks requiring self-referential cognition. Accordingly, 
DMN hypoconnectivity-and activity-renders ASD subjects unable to access their own mental self during both rest and task states-they are locked-out of their own mental self.

\subsection{Hypoactivity and-Connectivity within Midline DMN II-Weakening of Internally Oriented Cognition}

The midline DMN also mediate other forms of internally oriented cognition like episodic simulation or mental time travel [76-78], mind-wandering [79,80], social cognition including theory of mind [81-84], and autobiographical memory [82,85-87]. While autobiographical memory and social cognition/theory of mind have received coverage showing well-known deficits in ASD, the situation is less clear for mental time travel, that is, episodic simulation of past, present, and future. Data in healthy subjects show strong association of episodic simulation with midline DMN [76-78]. One would consequently expect DMN hypoconnectivity in ASD to lead to deficits in episodic simulation, which has indeed been observed in some psychological studies [2,88,89].

How can DMN hypoactivity and connectivity impair the ASD subjects' ability of mental time travel of their own self? We tentatively hypothesize that the neuronal desynchronization between anterior and posterior midline DMN regions, as indexed by their reduced functional connectivity in both rest and task, may make it impossible for them to virtually expand their present self into both past and future on the mental level: the lower the anterior-posterior midline functional connectivity, the lower the degree of their synchronization, and the less subjects may mentally be able to virtually expand their present self into past and futures selves (as that requires expansion of neural activity across both anterior and posterior midline DMN) [76-78]. Such anterior-posterior DMN-based decreased temporal expansion into past and future selves is well compatible with both decreased midline DMN rsFC as well as phenomenological reports of increased interruption and desynchronization of past and future with the present self in ASD [90-93].

Other forms of internally oriented cognition like mind-wandering, social cognition, and autobiographical memory retrieval may also be affected by desynchronization of anterior-posterior midline DMN. For instance, mind-wandering and its spontaneous thoughts [94] are well known to recruit midline DMN regions as standing in a balance with lateral prefrontal cortex, i.e., central executive network (CEN) $[79,80,95]$. If the DMN is hypoactive during both rest and task, the DMN-CEN balance is also abnormal, as it has indeed been shown in ASD [67,96-98]. On a more cognitive level, DMN-CEN disbalance towards the dorsolateral prefrontal cortex may result in abnormally increased rationality and systematizing in cognition, i.e., hypersystematizing [11]. In contrast, motivation/reward and affective components of the self as mediated by especially anterior DMN [99-101] may be suppressed in both internally and externally oriented thoughts, as is indeed typical for ASD [11]. Finally, social cognition is also well known to be mediated by midline DMN in conjunction with TPJ and other temporal regions [83,102-104]. Decreased connectivity and thus reduced synchronization among these regions may again impair the integration of the various internal and external inputs and ultimately block access to the cognition of the other on a mental level, including its distinction from the own mental self.

Taken together, the reduced activity and connectivity of anterior and posterior midline DMN carries major consequences for not only the self, i.e., reduced self-referentiality with weakened mental self, but also for various forms of internally oriented cognition. In the same way that access to the mental self is diminished, access to other forms of internally oriented mental activity is also most likely reduced, including mental time travel/episodic simulation, the balancing of affective and cognitive components within the self and its thoughts, and social cognition with self-other distinction. Decreased anterior and posterior midline DMN may thus lock-out the autistic subjects from the internally oriented cognition of their own mental self-both self and internally oriented cognition no longer show self-expansion or self-prioritization [105-107]. 


\subsection{Abnormal DMN-Non-DMN and Subcortical-Cortical Topography-Increased Ego-Centredness}

In addition to the within-DMN task and rest changes, the DMN is also abnormally connected to various non-DMN regions in ASD. This includes a differential connectivity pattern of anterior and posterior midline DMN to temporal cortex, prefrontal cortex, and subcortical regions like AMG, HC, and PHC, and CRE. Although not fully consistent, the findings converge on decreased anterior DMN connectivity to prefrontal and temporal cortical regions while posterior midline DMN seemingly exhibits the opposite pattern, namely, increased connectivity. Moreover, functional connectivity of anterior and posterior midline DMN to subcortical AMG, $\mathrm{HC}$, and PHC is mostly decreased, whereas the DMN is too strongly connected with CRE. Together, these findings, albeit tentative due to some inconsistencies, suggest an overall change in the brain's topography with altered DMN-non-DMN balances on the cortical level and altered subcortical-cortical balance.

How is such potentially altered subcortical-cortical and DMN-non-DMN topography related to the paradox of the autistic self? A recent large meta-analysis in healthy subjects suggests a multilayered, nested hierarchical model of self [58]. There is a basic or lower layer of self, an interoceptive self that is related to regions that mostly process interoceptive stimuli from the own body, that is, insula, dorsal ACC, THA, and PHC, thus including mainly regions of the salience network $[58,108]$. The next or middle layer of self includes what Qin et al. (2020) describe as exteroceptive self that recruits insula, interior frontal gryus, premotor cortex, TPJ, and MPFC: these regions process exteroceptive and proprioceptive inputs, thus extending beyond the own body to the social world [58]. Finally, there is the most upper layer of the mental self that recruits all of the above-mentioned regions as well as more extensive anterior and posterior midline DMN regions-as this is mainly induced during typical self-referentiality paradigms, the authors speak of a mental self [58]. Since the regions of the lower layers all resurface in and are complemented by additional regions in the upper layers, Qin et al. (2020) speak of a nested neural hierarchical model of self with the interoceptive self as the bottom and the mental self at the top of the hierarchy [58].

How does this neural multilayered nested hierarchical model of self stand in relation to the self in ASD? The findings are clear. The uppermost layer of the mental self and its DMN at the top of the hierarchy are impaired and blocked for the ASD subject, who is thus locked-out from both its DMN and mental self. Albeit not fully consistent, the resting state connectivity pattern suggests that non-DMN regions like the temporal lobe and the subcortical regions stand in abnormal balance to the anterior and posterior midline DMN. As these abnormally connecting non-DMN and subcortical regions include some of those implicated in intero- and exteroceptive layers of self, we assume that the brain's topography is restricted towards processing intero- and exteroceptive processing layers of self (or bodily and environmental self, as described by Qin et al. 2020) while its DMN-based mental layers remain blocked [58] (see Figure 7).

This may shift the hierarchy and its balance: the intero- and exteroceptive self, i.e., physical self, may become isolated from their mental realization, including self-awareness and self-other distinction. The self is consequently focused on its physical aspects, i.e., intero- and/or exteroceptive self, while, at the same time, being locked-out from its mental self. This may account for the extreme degrees of ego-centeredness of ASD subjects: they can neither access their own self nor others' selves on the mental level, which leaves them with no choice but to focus on the more physical layers of their own self, i.e., ego-centeredness. Whether such restriction to the intero- and exteroceptive layers of their self can also account for the often-observed abnormalities in sensory input processing with abnormally strong perceptual experiences $[18-22,109,110]$ remains to be shown in the future. 


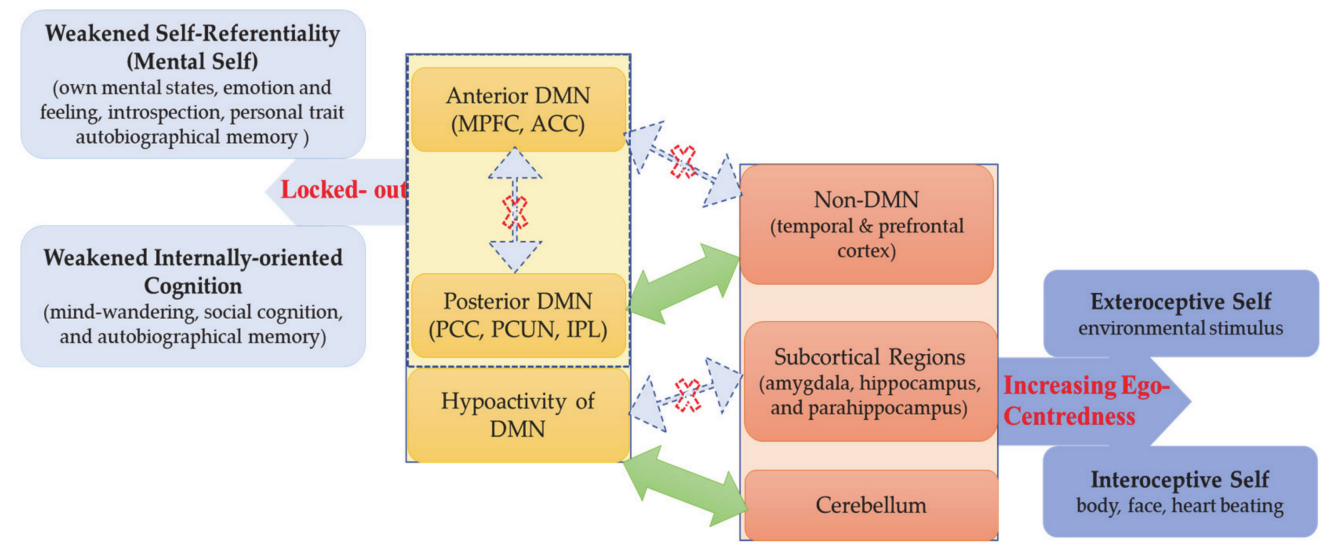

Figure 7. Hierarchical Model of Autistic Self (HAS): locked-out mental-self and increased ego-centeredness in individuals with ASD.

\subsection{Relationship to Other Theories I: Predictive Coding and the Hierarchical Model of Self}

Predictive coding is about the prediction of an input and its degree of divergence from the actual input, i.e., the prediction error [111,112]. Importantly, there is hierarchy of predicted inputs and predictions within the brain itself. Specifically, higher levels provide a predicted input for the lower layers' actual input: higher levels may predict the input processed in the next lower level, which, in turn, provides a predicted input for the next lower level and so forth. There is thus a nested hierarchy of predicted inputs and prediction error within the brain itself, an internal generative model, which is matched and compared with the hierarchy of external inputs stemming from body and environment [111].

This model of predictive coding has also been applied to ASD; one of the key proponents is Jacob Hohwy, who proposes that the internal generative model of the brain shows a flatter hierarchy in ASD [29]. Specifically, he proposes that the uppermost layer is thinner in ASD with lower number of nodes, while the lower layers of the internal generative model may, as compensation, be enriched with more nodes than in neurotypical subjects. Moreover, Perrykkad and Howhy (2019) assume that the upper layer provides a longer time and space scale than the lower layers, whose time-space scales are more restricted [29]. This means that prediction error minimization through predicted input focuses on short-term prediction, while long-term prediction is more or less neglected due to the sparsened most upper layer.

The autistic self is associated with more short-term features and details, as is well manifest in the sometime amazing autistic subjects' tendency to pick up details that we, as neurotypicals, would overlook - this is one key feature of the weak central coherence theory (WCC; see below for details) [113-116]. However, conceived in a longer temporal perspective, the autistic self will lack temporal continuity and persistence-it becomes temporally fragmented and modular as it is "sliced up" into distinct self-fragments of different durations without temporal transitions or "glue" [29,93]: "In the case of the autistic self, this would mean that long-term invariances (as captured in the idea of personal identity over time and space) are more poorly represented than short-term, context-specific self-inferences." [29] (p.17).

The temporal differences between upper and lower layers carry important implications for the model of self, which, in the predictive coding framework of Hohwy, occupies the role as hidden cause [29]. In ASD, the self, due to the disruption of the DMN and its longer timescales [117], is more based on short-term features of the lower layers and their higher variability as they are prone to and perturbed by the continuous external input-this concerns mainly sensory and interoceptive regions of the brain, like in the two lower layers accounting for the intero- and exteroceptive self in the hierarchical model of Qin et al. (2020) [58].

In contrast, weakening of the anterior and posterior midline DMN decreases the strength of the more long-term upper layer, which leaves the self without any psychological 
or mental stabilization independent of the ongoing perturbing inputs at the lower layers. Accordingly, we assume that the shift in the internal generative model with a weakening of the upper layer in Perrykkad and Hohwy (2019) converges well with her suggested HAS [29] (see Figure 8 and Table 3). The altered hierarchy of the autistic self may thus be characterized also in terms of temporal and spatial extension: the disruption of their mental self and its DMN leaves the autistic self with much more restricted time and space scales as limited to the ones of lower cortical and subcortical regions. Let us expand upon that in the following.

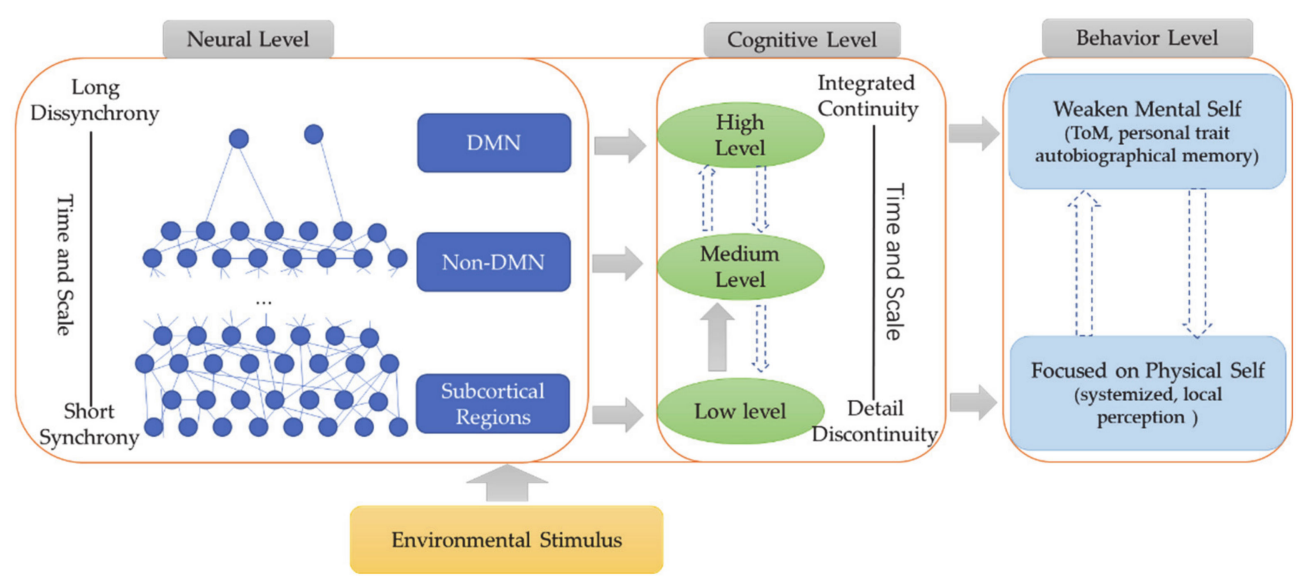

Figure 8. The altered hierarchy of the autistic self on neural, cognitive, and behavioral levels in ASD.

Table 3. Summary of the relationship between the Hierarchical Model of Autistic Self (HAS) and other theories.

\begin{tabular}{|c|c|c|c|c|c|}
\hline \multicolumn{3}{|c|}{ HAS } & \multirow{2}{*}{ PC } & \multirow{2}{*}{ WCC } & \multirow{2}{*}{ TOMМ } \\
\hline DMN & INTs & Self & & & \\
\hline $\begin{array}{l}\text { 1.Hypoactivity of DMN; } \\
\text { 2.Hypoconnectivity } \\
\text { between anterior and } \\
\text { posterior DMN; } \\
\text { 3.Hypoconnectivity } \\
\text { between anterior DMN } \\
\text { and non-DMN; }\end{array}$ & $\begin{array}{l}\text { Reduced internal } \\
\text { temporal continuity }\end{array}$ & $\begin{array}{l}\text { Locked-out } \\
\text { mental self } \\
\text { and internally } \\
\text { oriented cognition }\end{array}$ & $\begin{array}{l}\text { Lack of } \\
\text { long-term } \\
\text { prediction } \\
\text { (internal- } \\
\text { orientation) }\end{array}$ & $\begin{array}{l}\text { Overlook large } \\
\text { pictures (global) }\end{array}$ & $\begin{array}{l}\text { Hard to encode } \\
\text { large scale } \\
\text { of external } \\
\text { social stimulus }\end{array}$ \\
\hline $\begin{array}{l}\text { 1.Hypoconnectivity } \\
\text { betwwen DMN and } \\
\text { subcortical regions; } \\
\text { 2.Hyperconnectivity } \\
\text { between DMN and } \\
\text { cerebellum }\end{array}$ & $\begin{array}{l}\text { Increased external } \\
\text { temporal continuity }\end{array}$ & $\begin{array}{l}\text { Increasing Ego- } \\
\text { centeredness }\end{array}$ & $\begin{array}{l}\text { Focused on } \\
\text { short-term } \\
\text { prediction } \\
\text { (external- } \\
\text { orientation) }\end{array}$ & $\begin{array}{l}\text { Pick up } \\
\text { details (local) }\end{array}$ & $\begin{array}{l}\text { Tend to encoding } \\
\text { short scale } \\
\text { of external } \\
\text { social stimulus }\end{array}$ \\
\hline
\end{tabular}

Note: HAS—Hierarchical Model of Autistic Self; DMN—default-mode network; INTs—intrinsic neural timescales; PC—predictive coding; WCC — weak central coherence; TOMM-Theory of Mind Mechanisms.

\subsection{Relationship to Other Theories II: From Predictive Coding to Intrinsic Neural Timescales}

Considered in this way, the changes in the autistic self may ultimately be traced to a shift from longer intrinsic neural timescales of the DMN to the shorter ones of cortical and subcortical non-DMN regions-there may thus be a temporal basis of the self-disturbance in ASD. Albeit tentatively, this is indeed in line with two recent papers showing abnormal intrinsic neural timescales in cortical and subcortical regions in ASD [118,119]. Reduced internal temporal continuity of self may be compensated for by increasing external temporal continuity in one's action, such as by stereotypies, ritualization, rigidity, and obsessivecompulsive-like behavior [93], which decrease the prediction error and thereby provide internal temporal continuity [29]. 
Following the more externally oriented or ecological prediction, ASD subjects create their ecological niche in the external environment in terms of maximal stability and continuity: this helps avoiding surprises in the input in order to minimize their disruptive and unpredictable effects for the already temporally unstable short-term internal self-the authors speak of a highly inflexible precision of prediction errors in autism account (HIPPEA), which can be conceived more of an ecological rather than cognitive model of ASD [120-122]. Together, this amounts to a reversal between internal and external temporal continuity in ASD compared to neurotypical subjects: while neurotypical subjects use the internal temporal continuity to stabilize their self across time, ASD subjects may be forced to rely more on external temporal continuity to establish temporal continuity of their self.

Such temporal (and also spatial) approach to the lost hierarchy of self in ASD, i.e., HAS, is well compatible with the assumption of ASD being a temporo-spatial processing disorder that can be traced to the brain's dysconnectivity and dissynchrony [123]. The DMN shows decreased connectivity, which reflects decreased synchronization between anterior and posterior midline DMN - that, as explicated above, may lead to the loss of temporal integration and longer timescales on the psychological level, such as, for instance, in mental self and episodic simulation. Loss of longer timescales on the neural level of DMN may thus transform into corresponding loss of temporal continuity of self and temporal expansion during episodic simulation-loss of longer timescales thus provides a "common currency" of neural and psychological levels $[124,125]$ of the self and its internally oriented cognition in ASD (see Figure 8 and Table 3). However, to support such hypothesis, future studies may want to combine the investigation of neural dynamics like autocorrelation window with the measurement of psychological dynamics in episodic simulation, mental self, and mind-wandering.

\subsection{Relationship to Other Theories III: Temporal Extension of Weak Central Coherence Theory}

One highly influential theory is the WCC mainly promoted by Frith and Happe $[113,126-128]$. The key point here is that ASD subjects lack the coherence of linking different contents to their respective context; autistic subjects may thus be able to excel in mathematics or engineering but have problems of grasping more context-related subject matters, including languages. They often think about things in the smallest parts and their full details but are not able to see them in their larger spatiotemporal context-they cannot perceive or cognize the larger picture, that is, the "wood for the trees". There is thus a disbalance between local and global cognitive activity, with the latter being impaired while the former may be abnormally strong. While there has been some controversy about the WCC $[129,130]$, there is also strong support for the predominantly local-regional character of both perception and cognition in ASD [131-133].

We here would like to link the WCC to the reduction of the mental self and its abovementioned deficit in internally oriented cognition. The anterior and posterior midline DMN mediate episodic simulation, the virtual expansion of the present time point into both past and future [76,78]. The various events or contents that physically have taken place at one specific timepoint may thereby be detached and shifted to another purely virtual time point in the subjects' imagination, i.e., mental time travel. External inputs may thus be integrated within such internally ongoing virtual expansion of time of present into past and future.

As detailed above, DMN hypoactivity and connectivity in ASD subjects may make impossible such virtual expansion of inputs, which then restricts their cognition to (temporally) local levels of the present while blocking more global extension into past and future. Accordingly, we conceive the WCC in a temporal and dynamic way, which allows us to frame the relation of local vs. global perception/cognition as relation between shorter and longer intrinsic neural timescales (see Table 3). Future studies may want to probe some of the typical WCC tasks in conjunction with a temporal dynamic analysis on both 
psychological and neural grounds (see Watanabe et al., 2019 [118] and Damiani et al., 2019 [119] for a first step).

\subsection{Relationship to Other Theories IV: Theory of Mind Mechanisms (TOMM) and Their Temporal Basis}

Yet another influential theory is the Theory of Mind Mechanisms (TOMM) [5-7]. Here, the pronounced social cognition deficits are supposed to be based on deficits of imagining another person's minds on a cognitive level $[6,134]$. That is complemented by a more precognitive and prereflective account in phenomenology where changes in different levels of intersubjectivity (primary precognitive, secondary-cognitive, and tertiary-metacognitive) are assumed in ASD (see Nilsson et al., 2019, 2020 for overview [91,92]).

We suppose that both cognitive and precognitive changes in intersubjectivity can ultimately be traced to the issue of temporal (and spatial) scales: if the range of the self's internal temporal scales is rather limited and short, the person will have difficulties encoding and attuning to the much larger scales of its external environmental context-the subject will thus be socially isolated. In contrast, a wide range of different temporal scales, including both short and long, may allow the internal self to much more strongly connect and synchronize with its external environment-the subject will be well integrated. Accordingly, the limited range of timescales with the potential loss of especially the longer ones of the DMN may restrict the autistic self's capacity to attune and synchronize with the large range of different, i.e., short and long, timescales of its environment-social isolation may be traced to temporal isolation (see Table 3).

\section{Conclusions-A Hierarchical and Spatiotemporal Approach to the Autistic Self}

We reviewed the neural findings on the self in ASD. One key finding is decreased activity of anterior and posterior midline DMN regions during different self-specific tasks, thus indicating a domain-general DMN deficit. Additionally, anterior and posterior midline DMN regions show decreased functional connectivity among each during both rest and task states accompanied by abnormal connectivity to non-DMN regions, including frontal, temporal, subcortical, and cerebellum.

Drawing on a recently introduced multilayered nested hierarchical model of self [58], we propose that those with ASD suffer from a DMN-based deficit in the mental self, accounting for the weakened self-referentiality with decreases in both self-awareness and self-other distinction. ASD subjects are locked-out of their mental self. That, in turn, leads to a disbalance of the weakened if not absent mental self with the lower layers of self, the intero- and exteroceptive selves as variants of the physical self. The combination of a DMN-based abnormally weakened mental self with a non-DMN and subcortically based abnormally strengthened processing of intero- and exteroceptive self may account for the seemingly paradoxical co-occurrence of increased ego-centeredness and decreased self-referentiality in ASD, i.e., the paradox of self [26]. Together, this amounts to what we describe as Hierarhical Model of Autistic Self (HAS).

Reviewing the various findings and discussing different theories, we propose converging the HAS with a primarily temporal and spatial framework. Our review establishes that the spatial topography of DMN is altered in the brain of those with ASD and that these changes disturb the neural hierarchy of self with the disbalance of mental and physical layers of self. Initial findings suggest that these changes in DMN may go along with altered intrinsic neural timescales in the same regions $[118,119]$ - if replicated and confirmed this would render the self-disorder in ASD a truly spatial and temporal disorder conforming to what has been recently introduced as "Spatiotemporal Psychopathology" [78,135,136].

Specifically, combined spatial and temporal DMN changes make it rather difficult if not impossible for the autistic self to extend its physical self in spatial and temporal regard and thereby to constitute its own self on the mental or psychological level. The autistic self is consequently limited to the smaller time and space scales of its physical self, i.e., intero- and exteroceptive self, as mediated by subcortical and cortical non-DMN regions. This restriction of the autistic self, including its internally oriented cognition 
to shorter timescales and less extended spatial scales, leaves it socially isolated from its temporo-spatially more extended and complex environmental context.

In sum, the autistic self is locked-out of the larger timespace scales of the DMN and its mental self while being limited to the smaller timespace scales of its subcortical and cortical non-DMN-based intero- and exteroceptive self, i.e., physical self. Such spatiotemporal approach to the autistic self does not only explain the self-paradox but also aligns well with and extends dominant theories of ASD like predictive coding and weak central coherence theory. We conclude that our hierarchical and spatiotemporal model of the autistic self, i.e., HAS, opens novel and more specific ways of therapeutic intervention to re-balance the altered spatiotemporally based neural hierarchy of self.

Author Contributions: F.L. performed conceptualization, data curation, formal analysis, and visualization and wrote the original draft. G.N. conceived the idea, designed and supervised the study, wrote, revised, and edited the manuscripts. All authors have read and agreed to the published version of the manuscript.

Funding: This research was funded by the Humanities and Social Sciences Project of Ministry of Education of China, grant number17YJC880058.

Institutional Review Board Statement: Not applicable.

Informed Consent Statement: Not applicable.

Conflicts of Interest: The authors declare no conflict of interest.

\section{References}

1. Terrett, G.; Rendell, P.G.; Raponi-Saunders, S.; Henry, J.D.; Bailey, P.E.; Altgassen, M. Episodic Future Thinking in Children with Autism Spectrum Disorder. J. Autism Dev. Disord. 2013, 43, 2558-2568. [CrossRef] [PubMed]

2. Lind, S.E.; Williams, D.M.; Bowler, D.M.; Peel, A. Episodic memory and episodic future thinking impairments in high-functioning autism spectrum disorder: An underlying difficulty with scene construction or self-projection? Neuropsychology 2014, $28,55-67$. [CrossRef] [PubMed]

3. Cygan, H.B.; Marchewka, A.; Kotlewska, I.; Nowicka, A. Neural Correlates of Reflection on Present and Past Selves in Autism Spectrum Disorder. J. Autism Dev. Disord. 2019, 49, 1267-1277. [CrossRef] [PubMed]

4. Hogeveen, J.; Krug, M.K.; Geddert, R.M.; Ragland, J.D.; Solomon, M. Compensatory Hippocampal Recruitment Supports Preserved Episodic Memory in Autism Spectrum Disorder. Biol. Psychiatry Cogn. Neurosci. Neuroimaging 2020, 5, 97-109. [CrossRef]

5. Senju, A.; Southgate, V.; White, S.; Frith, U. Mindblind eyes: An absence of spontaneous theory mind in Asperger Syndrome. Science 2009, 325, 883-885. [CrossRef]

6. Baron-Cohen, S.; Leslie, A.M.; Frith, U. Does the autistic child have a "theory of mind"? Cognition 1985, 21, 37. [CrossRef]

7. Firth, U. Mind Blindness and the Brain in Autism. Neuron 2001, 32, 969-979. [CrossRef]

8. Harmsen, I.E. Empathy in Autism Spectrum Disorder. J. Autism Dev. Disord. 2019, 49, 3939-3955. [CrossRef]

9. Tanaka, J.W.; Sung, A. The "Eye Avoidance" Hypothesis of Autism Face Processing. J. Autism Dev. Disord. 2016, 46, 1538-1552. [CrossRef]

10. Kinnaird, E.; Stewart, C.; Tchanturia, K. Investigating alexithymia in autism: A systematic review and meta-analysis. Eur. Psychiat. 2019, 55, 80-89. [CrossRef]

11. Baron-Cohen, S.; Lombardo, M.V. Autism and talent: The cognitive and neural basis of systemizing. Dialogues Clin. Neurosci. 2017, 19, 345-353.

12. Bernier, R.; Dawson, G.; Webb, S.; Murias, M. EEG mu rhythm and imitation impairments in individuals with autism spectrum disorder. Brain Cogn. 2007, 64, 228-237. [CrossRef]

13. Dewey, D.; Cantell, M.; Crawford, S.G. Motor and gestural performance in children with autism spectrum disorders, developmental coordination disorder, and/or attention deficit hyperactivity disorder. J. Int. Neuropsychol. Soc. 2007, 13, 246-256. [CrossRef]

14. Chetcuti, L.; Hudry, K.; Grant, M.; Vivanti, G. Object-directed imitation in autism spectrum disorder is differentially influenced by motoric task complexity, but not social contextual cues. Autism 2019, 23, 199-211. [CrossRef]

15. Leekam, S.R.; Prior, M.R.; Uljarevic, M. Restricted and repetitive behaviors in autism spectrum disorders: A review of research in the last decade. Psychol. Bull. 2011, 137, 562-593. [CrossRef]

16. Matson, J.L.; Dempsey, T.; Fodstad, J.C. Stereotypies and repetitive/restrictive behaviours in infants with autism and pervasive developmental disorder. Dev. Neurorehabil. 2009, 12, 122-127. [CrossRef]

17. Watt, N.; Wetherby, A.M.; Barber, A.; Morgan, L. Repetitive and Stereotyped Behaviors in Children with Autism Spectrum Disorders in the Second Year of Life. J. Autism Dev. Disord. 2008, 38, 1518-1533. [CrossRef]

18. Simon, D.M.; Wallace, M.T. Dysfunction of sensory oscillations in Autism Spectrum Disorder. Neurosci. Biobehav. Rev. 2016, 68, 848-861. [CrossRef] 
19. Baum, S.H.; Stevenson, R.A.; Wallace, M.T. Behavioral, perceptual, and neural alterations in sensory and multisensory function in autism spectrum disorder. Prog. Neurobiol. 2015, 134, 140-160. [CrossRef]

20. Robertson, C.E.; Baron-Cohen, S. Sensory perception in autism. Nat. Rev. Neurosci 2017, 18, 671-684. [CrossRef]

21. Stevenson, R.A.; Siemann, J.K.; Woynaroski, T.G.; Schneider, B.C.; Eberly, H.E.; Camarata, S.M.; Wallace, M.T. Evidence for Diminished Multisensory Integration in Autism Spectrum Disorders. J. Autism Dev. Disord. 2014, 44, 3161-3167. [CrossRef]

22. Siemann, J.K.; Veenstra-VanderWeele, J.; Wallace, M.T. Approaches to Understanding Multisensory Dysfunction in Autism Spectrum Disorder. Autism Res. 2020, 13, 1430-1449. [CrossRef]

23. Lombardo, M.V.; Baron-Cohen, S. The role of the self in mindblindness in autism. Conscious. Cogn. 2011, 20, 130-140. [CrossRef] [PubMed]

24. Kanner, L. Autistic disturbances of affective contact. Nervous Child. 1943, 2, 217-250.

25. Asperger, H. Die "Autistischen Psychopathen" im Kindesalter. Archivf. Psychiatr. 1944, 117, 76-136. [CrossRef]

26. Lombardo, M.V.; Baron-Cohen, S. Unraveling the paradox of the autistic self. Wires Cogn. Sci. 2010, 1, 393-403. [CrossRef]

27. Williams, D. Theory of own mind in autism: Evidence of a specific deficit in self-awareness? Autism 2010, 14, 474-494. [CrossRef]

28. Uddin, L.Q. The self in autism: An emerging view from neuroimaging. Neurocase 2011, 17, 201-208. [CrossRef]

29. Perrykkad, K.; Hohwy, J. Modelling Me, Modelling You: The Autistic Self. Rev. J. Autism Dev. Dis. 2020, 7, 1-31. [CrossRef]

30. Uljarevic, M.; Hamilton, A. Recognition of Emotions in Autism: A Formal Meta-Analysis. J. Autism Dev. Disord. 2013, 43, 1517-1526. [CrossRef]

31. Harms, M.B.; Martin, A.; Wallace, G.L. Facial Emotion Recognition in Autism Spectrum Disorders: A Review of Behavioral and Neuroimaging Studies. Neuropsychol. Rev. 2010, 20, 290-322. [CrossRef] [PubMed]

32. Dapretto, M.; Davies, M.S.; Pfeifer, J.H.; Scott, A.A.; Sigman, M.; Bookheimer, S.Y.; Iacoboni, M. Understanding emotions in others: Mirror neuron dysfunction in children with autism spectrum disorders. Nat. Neurosci. 2006, 9, 28-30. [CrossRef] [PubMed]

33. Finnegan, E.G.; Asaro-Saddler, K.; Zajic, M.C. Production and comprehension of pronouns in individuals with autism: A meta-analysis and systematic review. Autism 2020, 230534210. [CrossRef] [PubMed]

34. Naigles, L.R.; Cheng, M.; Xu Rattanasone, N.; Tek, S.; Khetrapal, N.; Fein, D.; Demuth, K. “You're telling me!” The prevalence and predictors of pronoun reversals in children with autism spectrum disorders and typical development. Res. Autism Spect. Dis. 2016, 27, 11-20. [CrossRef]

35. Hobson, R.P.; Lee, A.; Hobson, J.A. Personal Pronouns and Communicative Engagement in Autism. J. Autism Dev. Disord. 2010, 40, 653-664. [CrossRef]

36. Silani, G.; Bird, G.; Brindley, R.; Singer, T.; Frith, C.; Frith, U. Levels of emotional awareness and autism: An fMRI study. Soc. Neurosci. UK 2008, 3, 97-112. [CrossRef]

37. Hill, E.; Berthoz, S.; Frith, U. Brief Report: Cognitive Processing of Own Emotions in Individuals with Autistic Spectrum Disorder and in Their Relatives. J. Autism Dev. Disord. 2004, 34, 229-235. [CrossRef]

38. Williams, D.; Happe, F. Representing intentions in self and other: Studies of autism and typical development. Dev. Sci 2010, 13, 307-319. [CrossRef]

39. Williams, D.M.; Happe, F. What did I say? Versus what did I think? Attributing false beliefs to self amongst children with and without autism. J. Autism Dev. Disord. 2009, 39, 865-873. [CrossRef]

40. Casassus, M.; Poliakoff, E.; Gowen, E.; Poole, D.; Jones, L.A. Time perception and autistic spectrum condition: A systematic review. Autism Res. 2019, 12, 1440-1462. [CrossRef]

41. Jurek, L.; Longuet, Y.; Baltazar, M.; Amestoy, A.; Schmitt, V.; Desmurget, M.; Geoffray, M. How did I get so late so soon? A review of time processing and management in autism. Behav. Brain Res. 2019, 374, 112121. [CrossRef]

42. Isaksson, S.; Salomäki, S.; Tuominen, J.; Arstila, V.; Falter-Wagner, C.M.; Noreika, V. Is there a generalized timing impairment in Autism Spectrum Disorders across time scales and paradigms? J. Psychiatr. Res. 2018, 99, 111-121. [CrossRef]

43. Robinson, S.; Howlin, P.; Russell, A. Personality traits, autobiographical memory and knowledge of self and others: A comparative study in young people with autism spectrum disorder. Autism 2017, 21, 357-367. [CrossRef]

44. Greimel, E.; Schulte-Rüther, M.; Kamp-Becker, I.; Remschmidt, H.; Herpertz-Dahlmann, B.; Konrad, K. Selbst- und Fremdbeurteilung der Empathie bei Jugendlichen mit Autismus. Z. Kinder Jugendpsychiatrie Psychother. 2011, 39, 113-121. [CrossRef]

45. Nicholson, T.; Williams, D.; Carpenter, K.; Kallitsounaki, A. Interoception is Impaired in Children, But Not Adults, with Autism Spectrum Disorder. J. Autism Dev. Disord. 2019, 49, 3625-3637. [CrossRef]

46. Nicholson, T.M.; Williams, D.M.; Grainger, C.; Christensen, J.F.; Calvo-Merino, B.; Gaigg, S.B. Interoceptive impairments do not lie at the heart of autism or alexithymia. J. Abnorm. Psychol. 2018, 127, 612-622. [CrossRef]

47. Palser, E.R.; Fotopoulou, A.; Pellicano, E.; Kilner, J.M. The link between interoceptive processing and anxiety in children diagnosed with autism spectrum disorder: Extending adult findings into a developmental sample. Biol. Psychol. 2018, 136, 13-21. [CrossRef]

48. Markram, K.; Markram, H. The intense world theory-a unifying theory of the neurobiology of autism. Front. Hum. Neurosci. 2010, 4, 224. [CrossRef]

49. Lind, S.E.; Williams, D.M.; Nicholson, T.; Grainger, C.; Carruthers, P. The self-reference effect on memory is not diminished in autism: Three studies of incidental and explicit self-referential recognition memory in autistic and neurotypical adults and adolescents. J. Abnorm. Psychol. 2020, 129, 224-236. [CrossRef]

50. Lau, W.K.W.; Leung, M.; Zhang, R. Hypofunctional connectivity between the posterior cingulate cortex and ventromedial prefrontal cortex in autism: Evidence from coordinate-based imaging meta-analysis. Prog. Neuro Psychopharmacol. Biol. Psychiatry 2020, 103, 109986. [CrossRef] 
51. D'Argembeau, A.; Collette, F.; Van der Linden, M.; Laureys, S.; Del, F.G.; Degueldre, C.; Luxen, A.; Salmon, E. Self-referential reflective activity and its relationship with rest: A PET study. Neuroimage 2005, 25, 616-624. [CrossRef] [PubMed]

52. Schneider, F.; Bermpohl, F.; Heinzel, A.; Rotte, M.; Walter, M.; Tempelmann, C.; Wiebking, C.; Dobrowolny, H.; Heinze, H.J.; Northoff, G. The resting brain and our self: Self-relatedness modulates resting state neural activity in cortical midline structures. Neuroscience 2008, 157, 120-131. [CrossRef] [PubMed]

53. Qin, P.; Northoff, G. How is our self related to midline regions and the default-mode network? Neuroimage 2011, 57, 1221-1233. [CrossRef] [PubMed]

54. Davey, C.G.; Pujol, J.; Harrison, B.J. Mapping the self in the brain's default mode network. Neuroimage 2016, 132, 390-397. [CrossRef]

55. Kolvoort, I.R.; Wainio-Theberge, S.; Wolff, A.; Northoff, G. Temporal integration as "common currency" of brain and self-scale-free activity in resting-state EEG correlates with temporal delay effects on self-relatedness. Hum. Brain Mapp. 2020, 41, 4355-4374. [CrossRef]

56. Wolff, A.; Di Giovanni, D.A.; Gomez-Pilar, J.; Nakao, T.; Huang, Z.; Longtin, A.; Northoff, G. The temporal signature of self: Temporal measures of resting-state EEG predict self-consciousness. Hum. Brain Mapp. 2019, 40, 789-803. [CrossRef]

57. Qin, P.; Grimm, S.; Duncan, N.W.; Fan, Y.; Huang, Z.; Lane, T.; Weng, X.; Bajbouj, M.; Northoff, G. Spontaneous activity in default-mode network predicts ascription of self-relatedness to stimuli. Soc. Cogn. Affect. Neurosci. 2016, 11, 693-702. [CrossRef]

58. Qin, P.; Wang, M.; Northoff, G. Linking bodily, environmental and mental states in the self-A three-level model based on a meta-analysis. Neurosci. Biobehav. Rev. 2020, 115, 77-95. [CrossRef]

59. Gillihan, S.J.; Farah, M.J. Is self special? A critical review of evidence from experimental psychology and cognitive neuroscience. Psychol. Bull. 2005, 131, 76-97. [CrossRef]

60. Uddin, L.Q. Brain connectivity and the self: The case of cerebral disconnection. Conscious. Cogn. 2011, 20, 94-98. [CrossRef]

61. Northoff, G.; Bermpohl, F. Cortical midline structures and the self. Trends Cogn. Sci. 2004, 8, 102-107. [CrossRef]

62. Northoff, G.; Heinzel, A.; de Greck, M.; Bermpohl, F.; Dobrowolny, H.; Panksepp, J. Self-referential processing in our brain-a meta-analysis of imaging studies on the self. Neuroimage 2006, 31, 440-457. [CrossRef]

63. Van der Meer, L.; Costafreda, S.; Aleman, A.; David, A.S. Self-reflection and the brain: A theoretical review and meta-analysis of neuroimaging studies with implications for schizophrenia. Neurosci. Biobehav. Rev. 2010, 34, 935-946. [CrossRef]

64. Murray, R.J.; Debbane, M.; Fox, P.T.; Bzdok, D.; Eickhoff, S.B. Functional connectivity mapping of regions associated with selfand other-processing. Hum. Brain Mapp. 2015, 36, 1304-1324. [CrossRef]

65. Frewen, P.; Schroeter, M.L.; Riva, G.; Cipresso, P.; Fairfield, B.; Padulo, C.; Kemp, A.H.; Palaniyappan, L.; Owolabi, M.; Kusi-Mensah, K.; et al. Neuroimaging the consciousness of self: Review, and conceptual-methodological framework. Neurosci. Biobehav. Rev. 2020, 112, 164-212. [CrossRef]

66. Chen, H.; Wang, J.; Uddin, L.Q.; Wang, X.; Guo, X.; Lu, F.; Duan, X.; Wu, L.; Chen, H. Aberrant functional connectivity of neural circuits associated with social and sensorimotor deficits in young children with autism spectrum disorder. Autism Res. 2018, 11, 1643-1652. [CrossRef]

67. Abbott, A.E.; Nair, A.; Keown, C.L.; Datko, M.; Jahedi, A.; Fishman, I.; Müller, R. Patterns of Atypical Functional Connectivity and Behavioral Links in Autism Differ Between Default, Salience, and Executive Networks. Cereb. Cortex 2016, 26, 4034-4045. [CrossRef]

68. Falahpour, M.; Thompson, W.K.; Abbott, A.E.; Jahedi, A.; Mulvey, M.E.; Datko, M.; Liu, T.T.; Müller, R. Underconnected, But Not Broken? Dynamic Functional Connectivity MRI Shows Underconnectivity in Autism Is Linked to Increased Intra-Individual Variability Across Time. Brain Connect. 2016, 6, 403-414. [CrossRef]

69. Yerys, B.E.; Gordon, E.M.; Abrams, D.N.; Satterthwaite, T.D.; Weinblatt, R.; Jankowski, K.F.; Strang, J.; Kenworthy, L.; Gaillard, W.D.; Vaidya, C.J. Default mode network segregation and social deficits in autism spectrum disorder: Evidence from nonmedicated children. NeuroImage Clin. 2015, 9, 223-232. [CrossRef]

70. Jann, K.; Hernandez, L.M.; Beck Pancer, D.; McCarron, R.; Smith, R.X.; Dapretto, M.; Wang, D.J.J. Altered resting perfusion and functional connectivity of default mode network in youth with autism spectrum disorder. Brain Behav. 2015, 5. [CrossRef]

71. Cheng, W.; Rolls, E.T.; Gu, H.; Zhang, J.; Feng, J. Autism: Reduced connectivity between cortical areas involved in face expression, theory of mind, and the sense of self. Brain 2015, 138, 1382-1393. [CrossRef] [PubMed]

72. Washington, S.D.; Gordon, E.M.; Brar, J.; Warburton, S.; Sawyer, A.T.; Wolfe, A.; Mease-Ference, E.R.; Girton, L.; Hailu, A.; Mbwana, J.; et al. Dysmaturation of the default mode network in autism. Hum. Brain Mapp. 2014, 35, 1284-1296. [CrossRef] [PubMed]

73. Babo-Rebelo, M.; Buot, A.; Tallon-Baudry, C. Neural responses to heartbeats distinguish self from other during imagination. Neuroimage 2019, 191, 10-20. [CrossRef] [PubMed]

74. Babo-Rebelo, M.; Richter, C.G.; Tallon-Baudry, C. Neural Responses to Heartbeats in the Default Network Encode the Self in Spontaneous Thoughts. J. Neurosci. 2016, 36, 7829-7840. [CrossRef] [PubMed]

75. Huang, Z.; Obara, N.; Davis, H.T.; Pokorny, J.; Northoff, G. The temporal structure of resting-state brain activity in the medial prefrontal cortex predicts self-consciousness. Neuropsychologia 2016, 82, 161-170. [CrossRef]

76. Schacter, D.L.; Addis, D.R.; Hassabis, D.; Martin, V.C.; Spreng, R.N.; Szpunar, K.K. The future of memory: Remembering, imagining, and the brain. Neuron 2012, 76, 677-694. [CrossRef]

77. Ostby, Y.; Walhovd, K.B.; Tamnes, C.K.; Grydeland, H.; Westlye, L.T.; Fjell, A.M. Mental time travel and default-mode network functional connectivity in the developing brain. Proc. Natl. Acad. Sci. USA 2012, 109, 16800-16804. [CrossRef]

78. Northoff, G. The brain's spontaneous activity and its psychopathological symptoms-"Spatiotemporal binding and integration". Prog. Neuro Psychopharmacol. Biol. Psychiatry 2018, 80, 81-90. [CrossRef] 
79. Christoff, K.; Irving, Z.C.; Fox, K.C.R.; Spreng, R.N.; Andrews-Hanna, J.R. Mind-wandering as spontaneous thought: A dynamic framework. Nat. Rev. Neurosci. 2016, 17, 718-731. [CrossRef]

80. Smallwood, J.; Schooler, J.W. The Science of Mind Wandering: Empirically Navigating the Stream of Consciousness. Annu. Rev. Psychol. 2015, 66, 487-518. [CrossRef]

81. Spreng, R.N.; Mar, R.A.; Kim, A.S. The common neural basis of autobiographical memory, prospection, navigation, theory of mind, and the default mode: A quantitative meta-analysis. J. Cogn. Neurosci. 2009, 21, 489-510. [CrossRef]

82. Spreng, R.N.; Grady, C.L. Patterns of brain activity supporting autobiographical memory, prospection, and theory of mind, and their relationship to the default mode network. J. Cogn. Neurosci. 2010, 22, 1112-1123. [CrossRef]

83. Schilbach, L.; Timmermans, B.; Reddy, V.; Costall, A.; Bente, G.; Schlicht, T.; Vogeley, K. Toward a second-person neuroscience. Behav. Brain Sci. 2013, 36, 393-414. [CrossRef]

84. Schilbach, L. Towards a second-person neuropsychiatry. Philos. Trans. R. Soc. Lond. B Biol. Sci. 2016, 371, 20150081. [CrossRef]

85. Warren, K.N.; Hermiller, M.S.; Nilakantan, A.S.; O’Neil, J.; Palumbo, R.T.; Voss, J.L. Increased fMRI activity correlations in autobiographical memory versus resting states. Hum. Brain Mapp. 2018, 39, 4312-4321. [CrossRef]

86. Philippi, C.L.; Tranel, D.; Duff, M.; Rudrauf, D. Damage to the default mode network disrupts autobiographical memory retrieval. Soc. Cogn. Affect. Neur. 2015, 10, 318-326. [CrossRef]

87. Ino, T.; Nakai, R.; Azuma, T.; Kimura, T.; Fukuyama, H. Brain activation during autobiographical memory retrieval with special reference to default mode network. Open Neuroimag. J. 2011, 5, 14-23. [CrossRef]

88. Crane, L.; Lind, S.E.; Bowler, D.M. Remembering the past and imagining the future in autism spectrum disorder. Memory 2013, 21, 157-166. [CrossRef]

89. Lind, S.E.; Bowler, D.M. Episodic memory and episodic future thinking in adults with autism. J. Abnorm. Psychol. 2010, 119, 896-905. [CrossRef]

90. Zukauskas, P.R.; Assumpção, J.F.B.; Silton, N. Temporality and Asperger's Syndrome. J. Phenomenol. Psychol. 2009, 40, 85-106. [CrossRef]

91. Nilsson, M.; Handest, P.; Carlsson, J.; Nylander, L.; Pedersen, L.; Mortensen, E.L.; Arnfred, S. Well-Being and Self-Disorders in Schizotypal Disorder and Asperger Syndrome/Autism Spectrum Disorder. J. Nerv. Ment. Dis. 2020, 208, 418-423. [CrossRef]

92. Nilsson, M.; Arnfred, S.; Carlsson, J.; Nylander, L.; Pedersen, L.; Mortensen, E.L.; Handest, P. Self-Disorders in Asperger Syndrome Compared to Schizotypal Disorder: A Clinical Study. Schizophr. Bull. 2020, 46, 121-129. [CrossRef]

93. Vogel, D.; Falter-Wagner, C.M.; Schoofs, T.; Kramer, K.; Kupke, C.; Vogeley, K. Interrupted Time Experience in Autism Spectrum Disorder: Empirical Evidence from Content Analysis. J. Autism Dev. Disord. 2019, 49, 22-33. [CrossRef]

94. Northoff, G. How Does the Brain's Spontaneous Activity Generate Our Thoughts: The Spatiotemporal Theory of Task- Unrelated Thought (STTT). In The Oxford Handbook of Spontaneous Thought: Mind-Wandering, Creativity, and Dreaming; Christoff, K., Fox, K.C.R., Eds.; Oxford University Press: Oxford, UK, 2018; pp. 55-70.

95. Christoffa, K.; Gordonb, A.M.; Smallwoodc, J.; Smitha, R.; Schooler, J.W. Experience sampling during fMRI reveals default network and executive system contributions to mind wandering. Proc. Natl. Acad. Sci. USA 2009, 106, 8719-8724. [CrossRef]

96. Lawrence, K.E.; Hernandez, L.M.; Bookheimer, S.Y.; Dapretto, M. Atypical longitudinal development of functional connectivity in adolescents with autism spectrum disorder. Autism Res. 2019, 12, 53-65. [CrossRef]

97. Walsh, M.J.M.; Baxter, L.C.; Smith, C.J.; Braden, B.B. Age group differences in executive network functional connectivity and relationships with social behavior in men with autism spectrum disorder. Res. Autism Spect. Dis. 2019, 63, 63-77. [CrossRef]

98. Plitt, M.; Barnes, K.A.; Wallace, G.L.; Kenworthy, L.; Martin, A. Resting-state functional connectivity predicts longitudinal change in autistic traits and adaptive functioning in autism. Proc. Natl. Acad. Sci. USA 2015, 112, E6699-E6706. [CrossRef]

99. Soch, J.; Deserno, L.; Assmann, A.; Barman, A.; Walter, H.; Richardson-Klavehn, A.; Schott, B.H. Inhibition of Information Flow to the Default Mode Network During Self-Reference Versus Reference to Others. Cereb. Cortex 2016. [CrossRef]

100. Amft, M.; Bzdok, D.; Laird, A.R.; Fox, P.T.; Schilbach, L.; Eickhoff, S.B. Definition and characterization of an extended socialaffective default network. Brain Struct. Funct. 2015, 220, 1031-1049. [CrossRef]

101. de Greck, M.; Rotte, M.; Paus, R.; Moritz, D.; Thiemann, R.; Proesch, U.; Bruer, U.; Moerth, S.; Tempelmann, C.; Bogerts, B.; et al. Is our self based on reward? Self-relatedness recruits neural activity in the reward system. Neuroimage 2008, 39, 2066-2075. [CrossRef]

102. Schilbach, L.; Bzdok, D.; Timmermans, B.; Fox, P.T.; Laird, A.R.; Vogeley, K.; Eickhoff, S.B. Introspective minds: Using ALE metaanalyses to study commonalities in the neural correlates of emotional processing, social \& unconstrained cognition. PLoS ONE 2012, 7, e30920. [CrossRef]

103. Schilbach, L.; Hoffstaedter, F.; Muller, V.; Cieslik, E.C.; Goya-Maldonado, R.; Trost, S.; Sorg, C.; Riedl, V.; Jardri, R.; Sommer, I.; et al. Transdiagnostic commonalities and differences in resting state functional connectivity of the default mode network in schizophrenia and major depression. Neuroimage Clin. 2016, 10, 326-335. [CrossRef] [PubMed]

104. Spreng, R.N.; Mar, R.A. I remember you: A role for memory in social cognition and the functional neuroanatomy of their interaction. Brain Res. 2012, 1428, 43-50. [CrossRef] [PubMed]

105. Sui, J.; Rotshtein, P.; Humphreys, G.W. Coupling social attention to the self forms a network for personal significance. Proc. Natl. Acad. Sci. USA 2013, 110, 7607-7612. [CrossRef] [PubMed]

106. Sui, J.; He, X.; Humphreys, G.W. Perceptual effects of social salience: Evidence from self-prioritization effects on perceptual matching. J. Exp. Psychol. Hum. Percept. Perform. 2012, 38, 1105-1117. [CrossRef] [PubMed]

107. Sui, J.; Humphreys, G.W. The Integrative Self: How Self-Reference Integrates Perception and Memory. Trends Cogn. Sci. 2015, 19, 719-728. [CrossRef] [PubMed] 
108. Menon, V. Large-scale brain networks and psychopathology: A unifying triple network model. Trends Cogn. Sci. 2011, 15, 483-506. [CrossRef]

109. Robertson, A.E.; David, R.S.R. The sensory experiences of adults with autism spectrum disorder: A qualitative analysis. Perception 2015, 44, 569-586. [CrossRef]

110. Stevenson, R.A.; Toulmin, J.K.; Youm, A.; Besney, R.M.A.; Schulz, S.E.; Barense, M.D.; Ferber, S. Increases in the autistic trait of attention to detail are associated with decreased multisensory temporal adaptation. Sci. Rep. UK 2017, 7. [CrossRef]

111. Friston, K. The free-energy principle: A unified brain theory? Nat. Rev. Neurosci. 2010, 11, 127-138. [CrossRef]

112. Hohwy, J. The Predictive Mind; Oxford University Press: Oxford, UK, 2013; pp. 41-57.

113. Frith, U.; Happé, F. Autism: Beyond "theory of mind". Cognition 1994, 50, 115-132. [CrossRef]

114. Baron-Cohen, S.; Ashwin, E.; Ashwin, C.; Tavassoli, T.; Chakrabarti, B. Talent in autism: Hyper-systemizing, hyper-attention to detail and sensory hypersensitivity. Philos. Trans. R. Soc. B Biol. Sci. 2009, 364, 1377-1383. [CrossRef]

115. Valla, J.M.; Belmonte, M.K. Detail-oriented cognitive style and social communicative deficits, within and beyond the autism spectrum: Independent traits that grow into developmental interdependence. Dev. Rev. 2013, 33, 371-398. [CrossRef]

116. Van Eylen, L.; Boets, B.; Steyaert, J.; Wagemans, J.; Noens, I. Local and Global Visual Processing in Autism Spectrum Disorders: Influence of Task and Sample Characteristics and Relation to Symptom Severity. J. Autism Dev. Disord. 2018, 48, 1359-1381. [CrossRef]

117. Golesorkhi, M.; Gomez-Pilar, J.; Tumati, S.; Fraser, M.; Northoff, G. Temporal hierarchy of intrinsic neural timescales converges with spatial core-periphery organization. bioRxiv 2021. [CrossRef]

118. Watanabe, T.; Rees, G.; Masuda, N. Atypical intrinsic neural timescale in autism. Elife 2019, 8. [CrossRef]

119. Damiani, S.; Scalabrini, A.; Gomez-Pilar, J.; Brondino, N.; Northoff, G. Increased scale-free dynamics in salience network in adult high-functioning autism. NeuroImage Clin. 2019, 21, 101634. [CrossRef]

120. Van de Cruys, S.; Evers, K.; Van der Hallen, R.; Van Eylen, L.; Boets, B.; De-Wit, L.; Wagemans, J.; Anderson, J.R. Precise Minds in Uncertain Worlds: Predictive Coding in Autism. Psychol. Rev. 2014, 121, 649-675. [CrossRef]

121. Constant, A.; Bervoets, J.; Hens, K.; Van de Cruys, S. Precise Worlds for Certain Minds: An Ecological Perspective on the Relational Self in Autism. Topoi 2020, 39, 611-622. [CrossRef]

122. Constant, A.; Ramstead, M.; Veissiere, S.; Campbell, J.O.; Friston, K.J. A variational approach to niche construction. J. R. Soc. Interface 2018, 15. [CrossRef]

123. Gepner, B.; Feron, F. Autism: A world changing too fast for a mis-wired brain? Neurosci. Biobehav. Rev. 2009, 33, 1227-1242. [CrossRef]

124. Northoff, G.; Wainio-Theberge, S.; Evers, K. Spatiotemporal neuroscience-What is it and why we need it. Phys. Life Rev. 2020, 33, 78-87. [CrossRef]

125. Northoff, G.; Lamme, V. Neural signs and mechanisms of consciousness: Is there a potential convergence of theories of consciousness in sight? Neurosci. Biobehav. Rev. 2020, 118, 568-587. [CrossRef]

126. Happé, F.; Frith, U. The Weak Coherence Account: Detail-focused Cognitive Style in Autism Spectrum Disorders. J. Autism Dev. Disord. 2006, 36, 5-25. [CrossRef]

127. Happe, F.G.; Booth, R.D. The power of the positive: Revisiting weak coherence in autism spectrum disorders. Q. J. Exp. Psychol. 2008, 61, 50-63. [CrossRef]

128. Happé, F.; Frith, U. Annual Research Review: Looking back to look forward - changes in the concept of autism and implications for future research. J. Child. Psychol Psyc 2020, 61, 218-232. [CrossRef]

129. Lopez, B.; Leekam, S.R. Do children with autism fail to process information in context? J. Child. Psychol. Psychiatry 2003, 44, 285-300. [CrossRef]

130. Mottron, L.; Burack, J.A.; Iarocci, G.; Belleville, S.; Enns, J.T. Locally oriented perception with intact global processing among adolescents with high-functioning autism: Evidence from multiple paradigms. J. Child. Psychol. Psychiatry 2003, 44, 904-913. [CrossRef]

131. Behrmann, M.; Thomas, C.; Humphreys, K. Seeing it differently: Visual processing in autism. Trends Cogn. Sci. 2006, 10, 258-264. [CrossRef] [PubMed]

132. Simmons, D.R.; Robertson, A.E.; McKay, L.S.; Toal, E.; McAleer, P.; Pollick, F.E. Vision in autism spectrum disorders. Vision Res. 2009, 49, 2705-2739. [CrossRef] [PubMed]

133. Van der Hallen, R.; Evers, K.; Brewaeys, K.; Van den Noortgate, W.; Wagemans, J. Global processing takes time: A meta-analysis on local-global visual processing in ASD. Psychol. Bull. 2015, 141, 549-573. [CrossRef] [PubMed]

134. Frith, U.; Morton, J.; Leslie, A.M. The cognitive basis of a biological disorder: Autism. Trends Neurosci. 1991, 14, 433-438. [CrossRef]

135. Northoff, G. Spatiotemporal psychopathology I: No rest for the brain's resting state activity in depression? Spatiotemporal psychopathology of depressive symptoms. J. Affect. Disord. 2016, 190, 854-866. [CrossRef]

136. Northoff, G. Spatiotemporal Psychopathology II: How does a psychopathology of the brain's resting state look like? Spatiotemporal approach and the history of psychopathology. J. Affect. Disord. 2016, 190, 867-879. [CrossRef] 